\title{
ALLOPURINOL BLOCKS THE FORMATION AND PROGRESSION OF AORTIC ANEURYSM IN A MOUSE MODEL OF MARFAN SYNDROME ACTING AS A SCAVENGER OF REACTIVE OXYGEN SPECIES
}

Sentence summary: Allopurinol prevents the formation and progression of Marfan syndrome aortopathy

Isaac Rodríguez-Rovira ${ }^{1, *}$, Cristina Arce ${ }^{1, *}$, Karo De Rycke ${ }^{1, *}, \pi$, Belén Pérez ${ }^{2}$, Aitor Carretero $^{3}$, Marc Arbonés ${ }^{1}$, Gisela Teixidò-Turà ${ }^{4}$, Mari Carmen Gómez-Cabrera ${ }^{3}$, Victoria Campuzano ${ }^{1,5}$, Francesc Jiménez-Altayó ${ }^{2}$ and Gustavo Egea ${ }^{1, \#}$

${ }^{1}$ Department of Biomedical Sciences, University of Barcelona School of Medicine and Health Sciences and IDIBAPS, 08036 Barcelona (Spain).

${ }^{2}$ Department of Pharmacology, Toxicology and Therapeutics, Neuroscience Instiute, School of Medicine, Autonomous University de Barcelona, 08193 Cerdanyola del Vallès, Spain.

${ }^{3}$ Department of Physiology, Faculty of Medicine, University of Valencia, CIBERFES, Fundación Investigación Hospital Clínico Universitario/INCLIVA, Valencia, Spain.

${ }^{4}$ Department of Cardiology, Hospital Universitari Vall d'Hebron, Barcelona, Spain. CIBER-CV, Vall d'Hebron Institut de Recerca (VHIR), Barcelona, Spain

${ }^{5}$ Centro de Investigación Biomédica en Red de Enfermedades Raras (CIBERER), ISCIII, Spain.

\# Corresponding author. Email: gegea@ub.edu (GE)

* These authors contributed equally to this work.

I Present address: Center for Medical Genetics, Department of Biomolecular Medicine, Ghent University, Ghent, 9000, Belgium. 


\begin{abstract}
The pathogenesis and progression of aortic aneurysm in Marfan syndrome (MFS) involves dysregulated TGF- $\beta$ and nitric oxide signaling, altered hemodynamics, and biomechanical forces. Increasing evidence indicates that redox stress participates in MFS aortopathy development, though its contribution is not well established. We reported elevated reactive oxygen species (ROS) formation and NADPH oxidase NOX4 upregulation in MFS mice and in patient aortic samples. Here we address the contribution of xanthine dehydrogenase $(\mathrm{XDH})$ which catabolizes purines into uric acid plus ROS. XDH mRNA and protein expression levels are increased in the aorta of young but not older MFS mice $\left(F b n 1^{C 1041 G /+}\right)$. The protein and enzymatic activity of the oxidase form $(\mathrm{XO})$ is increased with respect to the dehydrogenase. In patients, $\mathrm{XO}$ protein levels were increased in the dilated and the adjacent non-dilated zone of aortic aneurysm. The palliative administration of the XDH inhibitor allopurinol attenuated the progression of the aortic root aneurysm in MFS mice. Allopurinol was also protective when administrated before the appearance of aneurysm onset. MFSinduced elastic fiber fragmentation, fibrotic remodeling, nuclear translocation of pNRF2, and increased 3-nitrotyrosine levels in the aortic tunica media, as well as endothelial dysfunction, were all prevented by allopurinol. Mechanistically, allopurinol mediates these effects by inhibiting $\mathrm{H}_{2} \mathrm{O}_{2}$ overproduction, with no apparent relevance for uric acid, whose plasma levels remained constant with age. This study strengthens the concept that redox stress is an important determinant of aortic aneurysm formation and progression in MFS and supports a clinical trial for allopurinol in the pharmacological treatment of MFS aortopathy.
\end{abstract}




\section{INTRODUCTION}

Marfan syndrome (MFS) is a relatively common inherited rare disease $(1: 5,000$ individuals) of the connective tissue, caused by mutations in the gene encoding the extracellular matrix glycoprotein fibrillin-1 (1). This multisystem disease mainly affects the skeleton (abnormally long bones and spine deformations), eyes (lens dislocation) and aortic root aneurysm commonly leads to aortic dissection and rupture, the main reason for reduced life expectancy in MFS patients (2).

Reactive oxygen species (ROS) are essential mediators of cell physiology, modulating the activity of many signaling molecules (redox signaling). ROS are highly reactive chemicals formed from oxygen $\left(\mathrm{O}_{2}\right)$, including peroxides $\left(\mathrm{H}_{2} \mathrm{O}_{2}\right)$, superoxide $\left(\mathrm{O}_{2}{ }^{-}\right)$, and hydroxyl radical $\left(\mathrm{OH}^{-}\right)$as the primary, most frequently formed. However, when ROS are chronically overproduced, they contribute to pathogenesis (redox stress), causing transient or permanent damage to nucleic acids, proteins, and lipids (3). In the cardiovascular system, redox stress causes, among other processes, endothelial dysfunction, arterial remodeling, and vascular inflammation. ROS are also involved in the development of aortic aneurysms through the regulation of inflammation induction, matrix metalloproteinase (MMP) expression, vascular smooth muscle cell (VSMC) apoptosis, and phenotypic changes, as well as modifying extracellular matrix properties (4). The role of local redox stress (often simplified to oxidative stress) in the pathogenesis of aortic abdominal aneurysm is well documented in humans and murine models (5-10), but much less understood in thoracic aortic aneurysm (TAA) of genetic origin, such as in MFS and Loeys-Dietz syndrome (LDS) (11).

We and others have shown that ROS production is increased in MFS (1218 ), although their sources and impact on the formation and/or progression in either human or murine MFS aortic aneurysms is still not well established $(19,20)$. We recently reported the involvement of upregulated NADPH (nicotinamide adenine dinucleotide phosphate) oxidase 4 (NOX4) both in human and mouse MFS aortic samples and cultured VSMC. Nonetheless, besides NOX4, another important source of free radicals in the cardiovascular system is xanthine dehydrogenase $(\mathrm{XDH})$, which also goes by the alias xanthine oxidoreductase (XOR) (21-23).

$\mathrm{XDH} / \mathrm{XOR}$ is a rate limiting enzyme involved in the final steps of purine degradation, particularly in the conversion of hypoxanthine into xanthine and xanthine into urate. $\mathrm{XDH}$ is present in two interchangeable protein forms, $\mathrm{XDH}$ and xanthine oxidase $(\mathrm{XO})$, the former having greater abundance and affinity for $\mathrm{NAD}^{+}$. XDH is reversibly or irreversibly converted into $\mathrm{XO}$ by oxidation of the sulfhydryl residues or by proteolysis, respectively $(24,25)$. The XO-mediated enzymatic reaction is associated with the production of large amounts of $\mathrm{O}_{2}{ }^{-}$as well as $\mathrm{H}_{2} \mathrm{O}_{2}(26,27)$. XDH conversion into $\mathrm{XO}$ is favored by hypoxia, low $\mathrm{pH}$, ischemia, or the presence of $\mathrm{H}_{2} \mathrm{O}_{2}$ itself (27). XDH is present in the bloodstream and in the liver, intestine, myocardium, and vascular endothelium bound to cell surface glycosaminoglycans, and the enhancement of endothelium attached XDH favors the local production of ROS with subsequent endothelial dysfunction (2830 ). Increased levels of XDH have been reported in aortic samples from adult 
MFS mice (31) and LDS patients (32), yet the participation of XDH in TAA pathogenesis remains poorly understood.

Concomitantly to ROS production, XDH generates uric acid (UA), which in humans and great apes can pathologically accumulate in the plasma and some tissues. In rodents, UA is rapidly catabolized by uricase to allantoin, which is much more water soluble than UA (33). In humans, given the evolutionary loss of the uricase gene, UA can chemically react with $\mathrm{O}_{2}{ }^{-}$to generate allantoin. Allantoin is increased in the serum of chronic heart failure patients (34) and has been proposed as a biomarker for oxidative stress and a possible in vivo indicator of free radical concentrations in humans (35).

Several epidemiological studies suggest a relationship between elevated serum UA and cardiovascular risk, but this association remains controversial (36, 37 ). UA has a dual role in redox biology, acting as an antioxidant (both in vitro and in vivo) accounting for as much as $50 \%$ of the total antioxidant capacity of biological fluids in humans $(38,39)$. However, when UA accumulates in the cytoplasm or in acidic/hydrophobic milieu, it acts as a pro-oxidant promoting redox stress $(40,41)$. UA was found in the wall of human aortic aneurysms and atherosclerotic arteries (42) and there is a positive correlation between serum UA levels and aortic dilation and dissection (43-45). Epidemiologic and biochemical studies on UA formation have demonstrated that it is not only UA itself that leads to worse prognosis and increased cardiovascular events, but also ROS formed during $\mathrm{XDH}$ activity. These $\mathrm{XDH}$-derived $\mathrm{O}_{2}{ }^{-}$easily interact with endothelial cellgenerated nitric oxide (NO) forming, for example, peroxynitrite, which in turn diffuses to the adjacent aortic media layer. Here, the more ROS formed, the more irreversible chemical modifications to nucleic acids, proteins (tyrosine nitration), and lipids (lipid peroxidation) are produced $(3)(46,47)$. Therefore, the resulting combined action of excessively formed UA and free radicals, along with enhanced $\mathrm{XDH}$ activity, could significantly contribute to oxidative stress-linked pathological events such as endothelial dysfunction and heart failure (48).

We hypothesized that UA and/or ROS derived from an abnormal activity of aortic XDH participates in the formation and/or progression of the aortic aneurysm in MFS jointly with upregulated NOX4 (17)(49), where TGF $\beta$ turns out to be directly or indirectly pivotal. Thus, the dual aim of this study was firstly to investigate in detail the participation of XDH as a source of ROS and oxidative stress in MFS, and secondly, to evaluate the effectiveness of the XDH inhibitor allopurinol (ALO) (50) on the formation and progression of MFS-associated aortopathy. We report that XDH expression and activity are augmented in MFS aorta of young mice and MFS patients. ALO fully prevented both the formation and progression of the aortic aneurysm as well as the associated aortic wall degeneration. These effects were not mediated by changes in UA levels, which strikingly remained unaltered with age, but rather because ALO is primarily acting as a scavenger of ROS. Our results definitively highlight that redox stress is a significant driving force of MFS aortopathy and propose the popular and widely prescribed drug ALO as a feasible pharmacological therapeutic agent to prevent or attenuate aortic aneurysm progression in MFS.

\section{RESULTS}


The XO protein form is enhanced in the aorta of MFS patients.

To investigate the contribution of XDH in MFS, we first explored whether XDH expression is altered in the aorta of MFS patients subjected to aortic reparatory surgery. We evaluated both the aneurysmal (dilated) and the adjacent, apparently non-aneurysmal (non-dilated), aortic regions compared with virtually healthy aortae from heart donors (Figure 1). Compared with the healthy aorta, the aneurysmal aortic area of Marfan individuals (both non-dilated and dilated zones) showed an increase of the xanthine oxidase $(\mathrm{XO})$ protein form $(\sim 50 \mathrm{kDa})$ in detriment of the $\mathrm{XDH}$ form $(\sim 150 \mathrm{kDa})$, being, apparently, more severe in the non-dilated area of the aneurysm (Figure 1).

\section{XDH expression and XO enzymatic activity are both increased in the aorta of MFS mice.}

We next evaluated whether XDH mRNA and protein levels as well as enzymatic activity were also altered in the MFS mouse $\left(F b n 1^{C 1041 G /+}\right)$ aorta. We evaluated $X D H$ mRNA expression by RT-PCR in 3- and 6-month-old WT and MFS mice, ages in which the aortic root growth ratio is larger (51). MFS aorta of 3-monthold mice showed a significantly increased $X D H$ mRNA expression level compared with WT animals. Strikingly, this early age increase was not observed later (6 months-old) (Figure 2A).

Aortic XDH protein is revealed as a strongly labeled single band of $\sim 150 \mathrm{kDa}$ that corresponds to the $\mathrm{XDH}$ protein form itself, and a lower molecular weight band of $\sim 50 \mathrm{KDa}$ corresponding to the $\mathrm{XO}$ form (Figure $2 \mathrm{~B}$ ). The latter is generated from in vivo $\mathrm{XDH}$ proteolysis reflecting the characteristic unbalanced conversion between both enzymatic forms. Mouse liver, used as positive control, generates a strongly labeled high molecular weight doublet around $150 \mathrm{kDa}$ besides the $50 \mathrm{kDa}$ XO form (Figure 2B, liver lane) (52-55). Only MFS aortic lysates from 3-month-old mice showed an increased XO/XDH protein ratio compared with WT aortic lysates (Figure $2 \mathrm{~B})$. Immunohistochemistry with anti-XDH antibodies confirmed the increased expression of XDH in the aorta of young MFS mice, where intima and media layers showed significantly higher staining compared with their respective WT tunicae (Figure 2C).

To further support the greater presence of $\mathrm{XDH}$ in MFS aorta and to differentiate the contribution of the dehydrogenase $(\mathrm{XDH})$ and oxidase $(\mathrm{XO})$ forms, we measured their respective enzymatic activities in aorta lysates. In MFS aorta, the ratio obtained between $\mathrm{XO}$ and $\mathrm{XDH}$ activities was significantly higher in 3-monthold mice but not in 6-month-old mice (Figure 2D). Therefore, results indicate the major participation of the XO form. We utilized liver lysates as internal positive tissue control for both enzymatic activities, since XDH is highly expressed in this tissue (56) (Supplementary Figure 1). On average, the liver showed at least two-fold higher XDH and $\mathrm{XO}$ activities than the aorta (compare the respective $\mathrm{Y}$ axis values in Figure 2D/aorta and supplemental Figure 1A/liver). Altogether, our results confirm and add new information to that previously reported, where $\mathrm{XDH} / \mathrm{XOR}$ was upregulated in MFS mouse aorta (57). 


\section{Allopurinol prevents the formation and progression of aortic aneurysm in MFS mice.}

The observation that XDH is upregulated in young mouse and human MFS aortae, suggests its contribution to oxidative stress in MFS. Therefore, we hypothesized that the inhibition of its activity, with the consequent reduction of UA and ROS production should ameliorate aortic aneurysm progression. To test this hypothesis, we treated WT and MFS mice with the XDH inhibitor allopurinol (ALO). ALO is a safe, welltolerated, and cheap routinely prescribed drug to treat hyperuricemia in hyperuricemic and hypertensive patients (50)(58). Thus, we first treated 2-month-old WT and MFS mice with ALO in a palliative manner (PA) for a period of 16 weeks until 6 months of age (PA1; Supplementary Figure 2) and then evaluated aneurysm progression by ultrasonography. ALO significantly reduced the enlarged aortic root diameter occurring in MFS mice, the diameter obtained being similar to WT animals (Figure 3A1 and Supplementary Table 2). Note that ALO did not cause any alteration in the aortic root diameter of WT mice. Moreover, no sex differences were observed regarding the effectiveness of allopurinol (Supplementary Table 2)

We also evaluated the aortic wall organization in these mice by histomorphology, quantifying the number of large elastic fiber ruptures as previously defined (51). ALO treatment in MFS mice caused an apparent total normalization of elastic fiber organization and integrity, their overall morphology being indistinguishable from non-treated WT animals (Figure 3A2).

ALO has also been safely administered during the late stages of pregnancy, demonstrating efficiency in reducing uric acid, hypertension, and oxidative stress levels (59-62). Therefore, we next evaluated whether ALO also prevented the formation of the aneurysm. To this aim, ALO was administrated to pregnant and lactating female mice and then to weaning offspring until the age of 3 months (PE; supplementary Figure 2). ALO fully prevented the formation of the aneurysm (Figure 3B1 and supplementary Table 3), also showing a trend to reduce elastic fiber breaks (Figure 3B2).

\section{Allopurinol reduces $\mathrm{H}_{2} \mathrm{O}_{2}$ levels in MFS aorta altering neither XDH protein levels nor uric acid plasma concentrations.}

Next, we investigated the primary mechanism by which ALO so effectively prevents the formation and progression of the aneurysm. Considering that ALO is clinically prescribed to treat hyperuricemia, we first studied whether UA and its catabolite allantoin are altered in the blood plasma of MFS mice following ALO treatments. Strikingly, UA and allantoin plasma levels did not vary with age and neither did their ratio in MFS mice (Supplementary Figures 3A-C). In addition, as we observed that ALO treatment from 2 to 6 months of age was associated with prevention of aneurysm formation in MFS (PA1), we measured basal UA plasma levels at this age and they remained unaltered (Figure 4). The possibility that the inhibition of aneurysm progression was mediated by reducing the blood pressure was also discarded since systolic blood pressure values remained unaltered in both treated and non-treated MFS mice (Supplementary Figure 4) (63). ALO did not affect $\mathrm{XDH}$ expression in the MFS aortic intima and media layers (Supplementary Figure 5). This result was not unexpected as ALO is a hypoxanthine analogue that does not affect XDH expression (58). 
The observation that ALO induces neither the expected fall of UA plasma levels nor a decrease in XDH expression, leaves open the possibility that it acts by reducing the intrinsic high levels of redox stress, as inhibition of $\mathrm{XO}$ activity should also reduce ROS production $\left(\mathrm{O}_{2}^{-}\right.$and/or $\left.\mathrm{H}_{2} \mathrm{O}_{2}\right)$. ROS production is the result of the oxidation process mediated by $\mathrm{XO}$ using $\mathrm{O}_{2}$ as a cofactor generating $\mathrm{O}_{2}^{-}(64,65)$, and the subsequent reoxidation of the fully reduced $\mathrm{XO}$ produces $\mathrm{H}_{2} \mathrm{O}_{2}$ and two $\mathrm{O}_{2}^{-}$ species for every reduced $\mathrm{XO}$ (66). The $\mathrm{H}_{2} \mathrm{O}_{2} / \mathrm{O}_{2}$ ratio depends on the local $\mathrm{O}_{2}$ concentration and $\mathrm{pH}$ conditions, $\mathrm{H}_{2} \mathrm{O}_{2}$ being the major $\mathrm{ROS}$ produced under aerobic conditions (67), which is precisely what occurs in the heart and the ascending aorta. Therefore, we decided to measure the production of $\mathrm{H}_{2} \mathrm{O}_{2}$ both in plasma and in ascending aortic tissue. No differences were observed in $\mathrm{H}_{2} \mathrm{O}_{2}$ plasma levels between WT and MFS mice of different ages (Supplemental Figure 6). Nonetheless, since plasma $\mathrm{H}_{2} \mathrm{O}_{2}$ can come from diverse tissue sources, we next measured in situ $\mathrm{H}_{2} \mathrm{O}_{2}$ formation in freshly isolated ascending aortic rings ex vivo treated with ALO. MFS ascending aortic rings from 3 month-old mice produced larger amounts of $\mathrm{H}_{2} \mathrm{O}_{2}$ than WT littermates (Figure 5). Notably, ALO significantly reduced the overproduction of $\mathrm{H}_{2} \mathrm{O}_{2}$ in MFS aortic rings of 3 month-old mouse aortae, age at which the $\mathrm{XO}$ enzymatic activity (Figure 2D) and XDH mRNA and protein levels (Figures $2 A$ and $B$, respectively) are also significantly increased.

\section{Allopurinol prevents oxidative stress-associated injuries in the aortic media of MFS mice.}

Reactive nitrogen species (RNS) can be produced due to the interaction of endothelial-generated NO and XDH-induced ROS (68). Peroxynitrite and 3'nitrotyrosine (3-NT) products are considered reliable redox stress biomarkers. Immunohistochemical evaluation of 3-NT showed greater 3-NT levels in the tunica media of MFS aorta (Figure 6A and B). In both PA1 and PE experimental approaches, ALO significantly avoided this increase (Figures 6A and 6B, respectively).

The nuclear factor erythroid 2-related factor 2 (NRF2) is a key transcription factor that regulates the expression of several antioxidant defense mechanisms. Oxidative stress triggers its phosphorylation (pNRF2), being subsequently translocated to the nucleus to activate the expression response of physiological antioxidant enzymes $(69,70)$. Thus, we evaluated the nuclear presence of pNRF2 by immunofluorescence in aortic paraffin sections from WT and MFS mice treated with ALO after PA1 and PE treatments (Figure 6C and 6D, respectively). MFS aortic media showed a higher presence of nuclear pNRF2 in VSMC than WT VSMC. This result is demonstrative that the MFS aorta suffers redox stress, which in turn triggers the intrinsic endogenous antioxidant response. However, when ALO was administrated to MFS mice, the number of pNRF2 stained nuclei was indistinguishable from WT aorta, regardless the experimental treatment followed. This result is a logical consequence of the ALO-induced inhibition of the oxidative stress pathogenesis occurring in the MFS aorta.

Elastic fiber disruption in the MFS aorta is often accompanied by a compensatory fibrotic remodeling supported by collagen overexpression and/or organization rearrangements occurring mainly in the tunica media (71-73). This remodeling can be visualized under a polarized light microscope in paraffin- 
embedded aortae cross-sections stained with Picrosirius red. Green and red collagen fibers were observed, which is illustrative of their different fiber thickness and assembly compaction, and, therefore, of their degree of maturity (74). We observed an increase in collagen fibers in the aortic media of 6-month-old MFS (PA1 treatment), mainly due to a significant increase in immature (green) fibers, which is demonstrative of a fibrotic-like response. This reorganization is normalized after ALO treatment (Figure 7). In MFS aortae of 3-month-old animals (PE), the changes began to be appreciated, although no significant differences were reached (Supplementary Figure 7). Both PA1 and PE ALO treatments did not reduce the increased trend of mature (red) collagen fiber formation (Figure 7 and Supplementary Figure 7, respectively).

\section{Allopurinol prevents endothelial dysfunction in MFS ascending aorta.}

$\mathrm{XO}$ is the ROS source that could mediate alterations in the endothelialassociated vascular function by reducing $\mathrm{NO}$ bioavailability via direct interaction with $\mathrm{O}_{2}^{-}$(75). Previous evidence indicates that the MFS aorta shows endothelial dysfunction (57)(76,77). Here, we analyzed the potential therapeutic effects of ALO PA2 treatment (Supplementary Figure 2) on endothelial function. To this aim, wiremyography was used to measure the reactivity of endothelium-intact ascending aortas from 9-month-old MFS mice, age at which endothelial dysfunctions were more clearly observed (77). The experimental protocol followed is illustrated in Figure 8A. Aortic root diameter was also evaluated by ultrasonography in this mouse subset. As in 3- and 6-month-old MFS mice (Figure 3), the aneurysm was also inhibited after 28 weeks of ALO treatment (PA2) (Supplementary Figure 8 and Supplementary Table 4). Thereafter, ascending aortae were isolated, and vessels were contracted with $\mathrm{KCl}$ to check their functionality. All aortae responded similarly to $\mathrm{KCl}$ (Figure 8B). The relaxant response to Ach, mostly mediated by activation of endothelial NOS (eNOS/NOS3), is an indicator of endothelial function. Untreated MFS mice showed a reduced sensitivity $\left(\mathrm{pEC}_{50}\right)$ to endothelium-dependent $A C h$-induced relaxation compared with WT (the curve shifted to the right) (Figure 8C/asterisk and Supplementary Table 5), which indicates that ACh-mediated aortic relaxation is impaired in MFS mice in accordance with our (77) and others (76) previous observations. Importantly, ALO-treated MFS mice showed an ACh-induced relaxation that was indistinguishable from WT animals ( $\mathrm{pEC}_{50} 7.49 \pm 0.19$ and 7.52 \pm 0.10 , respectively) (Figure $8 \mathrm{C}$ and Supplementary Table 5), which proves that ALO treatment normalizes physiological endothelial function levels in MFS mice.

To check the participation of the NO/GC/cGMP pathway in the VSMC of untreated MFS mice, we next added increased concentrations of the NO donor sodium nitroprusside (NTP) to pre-contracted aortae with Phe and the non-selective NOS inhibitor L-NAME (Figure 8A), resulting in similar concentration-dependent vasodilatations in untreated MFS versus WT mice (Figure 8D). These results indicate that the observed impaired ACh responses in MFS aortae are demonstrative of endothelial dysfunction. No changes in the vasorelaxant response to NTP were observed in ALO-treated MFS mice (Figure 8D and Supplementary Table 5), indicating that the $\mathrm{NO} / \mathrm{GC} / \mathrm{cGMPc}$ signaling pathway is unaltered in MFS mice. Next, we also evaluated the $\alpha_{1}$-associated contractile response of ascending aortae when stimulated with Phe. No changes were observed either between untreated MFS and 
WT ascending aortae or following ALO treatment (Figure 8E and Supplementary Table 6), which demonstrates that ALO does not compromise the $\alpha_{1}$ response in tunica media-associated contractile function.

\section{DISCUSSION}

Despite the significant insights reported over the last two decades regarding the molecular mechanisms that participate in the formation and progression of aortic aneurysm in MFS, current pharmacological approaches (losartan, atenolol, or both together) have been proven to be of little use, or not useful enough to stop or even mitigate aortic aneurysm progression. Nowadays, only reparatory aortic surgery remains as the most effective therapy, but it has its limitations. Keeping this in mind, the aim of our study was, on the one hand, to obtain further insights into the contribution of XDH as a source of redox stress in the molecular pathogenesis of aortic aneurysm, and, on the other hand, to provide experimental evidence to support a new pharmacological approach with ALO, targeting oxidative stress in a well-established murine model of MFS (C1041G), but which at the same time might be assayed in a relatively straightforward manner in patients. XDH activity inhibition by ALO blocked or attenuated deleterious vascular events occurring in mouse MFS ascending aorta. Thus, we here demonstrated its effectiveness as an anti-redox stress drug, repositioning its use for blocking and reversing MFS-associated aortic disease based upon the XO/XDH ratio also being increased in MFS patients.

The main findings of this article are the following: (1) XDH is overexpressed in the ascending aorta of MFS patients and of young (3 month-old) MFS mice; (2) this upregulation is accompanied by increased enzymatic activity of the oxidase (XO) over the dehydrogenase (XDH) form; (3) XDH upregulation and overactivation in the aorta increases $\mathrm{ROS}$ production $\left(\mathrm{H}_{2} \mathrm{O}_{2}\right)$ in ascending aortic rings without changes in plasma UA levels; (4) the specific XDH inhibitor ALO prevents the formation and progression of aortic root dilation in MFS mice; (5) ALO inhibits redox stressassociated reactions such as the formation and accumulation of 3-NT, the nuclear translocation of pNRF2, and the collagen-associated fibrotic remodeling of the aortic media; and (6) ALO also prevents the characteristic MFS endothelial-dependent vasodilator dysfunction. Therefore, the present study indicates that XDH is upregulated in MFS, contributing to the associated redox stress and that ALO administration halts aortic aneurysm formation and progressive dilation of the ascending aorta in a mouse model of MFS. Mechanistically, ALO seems to mediate these effects by primarily reducing $\mathrm{H}_{2} \mathrm{O}_{2}$ levels and associated redox stress injuries acting as a ROS scavenger.

In MFS patients, XDH upregulation is favored towards the oxidase enzymatic form (XO). Interestingly, this is highly produced in the adjacent non-dilated zone of the aortic aneurysm. It is likely that in the dilated zone, where the histological damage is much more severe, the characteristic loss of VSMC explains the lesser expression observed. Notice that, in the dilated zone, there is a similar reduction of the XDH form compared with the non-dilated area. Most likely, the XO upregulation 
in the non-dilated zone is more representative of the molecular aortic injuries than the dilated zone since the structural changes are on their way to being produced but are not so dramatic as in the dilated zone where the aortopathy is already severe and irreversible.

$\mathrm{XDH}$ mRNA and protein expression levels, as well as XO enzymatic activity are significantly upregulated in MFS aortae in young (3-month-old) but not in older mice (6-month-old). It is possible that XDH upregulation only occurs while the aortic dilation undergoes rapid growth, which we observed occurs until 3 months of age, becoming slower in older animals (51). However, no differences between WT and MFS aortae have been reported regarding XDH activity in the study context of the aortic reactivity of MFS aorta (57), and of nitro-oleic acid as a mediator in ERK1/2 and NOS2 expression in MFS aortopathy (78). Explanations for this apparent discrepancy may be related to the different murine MFS models used $(\mathrm{mgR} / \mathrm{mgR}$ and Ang II infusion-induced acceleration of the aortopathy in MFS mouse, respectively), or the different $\mathrm{XDH}$ activity assays utilized, and/or even to local animal facility conditions.

We previously demonstrated the contribution of NOX4 in the progression of aortic aneurysm (17), but its precise role in the aortopathy was not assayed due to the absence of a clear selective inhibitor. Fortunately, this is not the case for XDH, with ALO being a well characterized specific inhibitor (79). The clinical actions of ALO are widely linked to UA-associated pathologies $(80,81)$. Nonetheless, ALO's mechanism of action also involves a concomitant reduction of ROS and, therefore, of oxidative stress, and, in the end, these two effects can probably explain most of its clinical efficacy. Strikingly, UA plasma levels in MFS mice were indistinguishable from those of WT, which was confirmed when we analyzed the plasma levels of allantoin, the end product of its catabolism, and the resulting unchanged ratio. To finally discard a UA-mediated effect in the blocking of aortic dilation progression after ALO treatment, plasma UA levels in ALO-treated mice were found to be unchanged. Both observations are demonstrative that the strong effect of ALO is not primary mediated through UA, but we cannot discard that lowering UA from normal baseline levels, interference from other metabolic pathways, or using other XDH inhibitors (for example, febuxostat) might also contribute to protection against redox stress.

It has been reported that ALO has a direct intrinsic scavenger effect on ROS, regardless of its XDH activity inhibition (82-85). When we tested this possibility by measuring ROS $\left(\mathrm{H}_{2} \mathrm{O}_{2}\right)$ production in freshly dissected ascending aortic rings where local aerobic and $\mathrm{pH}$ conditions favor $\mathrm{XDH}$ for $\mathrm{H}_{2} \mathrm{O}_{2}$ production, ALO fully prevented its formation. At the same time, characteristic pathological processes that usually accompany redox stress, such as the formation of 3-NT, pNRF2 nuclear translocation, and fibrotic remodeling responses were all reduced or fully avoided. The pathophysiological significance of these latter results in the MFS aortic media suggests several conclusions: (1) the accumulation of 3-NT is representative of abnormal RNS formation because of the pathological uncoupling of NO (86), which in turn leads to protein nitration via the formation of the highly reactive intermediate peroxynitrite and its subsequent product 3-NT (87). This 3-NT upsurge in MFS aortic media is consistent with the recent demonstration of $\mathrm{NO}$ uncoupling in aneurysm formation in both MFS mice and patients $(78)(88,89)$. Along this line of evidence, we previously identified actin as a significant nitrated protein target in MFS aorta 
from MFS patients (17), contributing in this manner to the reported damaged contractile properties of VSMC in MFS $(90,91)$; (2) redox stress is so elevated in MFS aorta that the intrinsic physiological antioxidant response mediated by the nuclear translocation of pNRF2 $(92,93)$ is not high enough to compensate it. In contrast, ALO treatment allows this compensation, normalizing, to a large extent, the endogenous redox levels in MFS aorta and reverting the subsequent redox stress modifications; and (3) the excessive accumulation of collagen (vascular fibrosis) and proteoglycans is characteristic of the aortic wall to compensate elastic fiber disarray $(94,95)$. In fact, this is the trend that we observe in the MFS media, where immature (green) collagen fibers are increased. ALO normalized, to a good extent, the content of green (immature) fibers, hence mitigating the fibrotic remodeling response that usually accompanies the aneurysm. It would be interesting to know whether ALO is also able to prevent the characteristic phenotypic switch of VSMC to a mixed contractile-secretory phenotype (95)(96), where besides a variety of contractile markers, the expression of COL $\alpha 1$ is enhanced and could, therefore, explain the abnormal expression and assembly of collagen fibers observed here.

Under physiological conditions, dehydrogenase is the basal activity form of $\mathrm{XDH}(97)$, but under pathological scenarios circulating XDH is rapidly converted to the XO form that mostly binds to the glycosaminoglycans of the apical (facing the blood stream) surface of vascular endothelial cells. This abnormal XO-associated endothelium interaction most likely increases local ROS rates, leading to endothelial dysfunctions (98). XDH is immunolocalized to the intima and media layers of WT aorta, both being overexpressed in MFS mice. We think that the increased XDH localization in the MFS aortic intima favors the local increase of 3-NT, which in turn is related to endothelial dysfunction. ALO fully normalized ACh-stimulated vasodilator function. It is no surprise that ALO is responsible for the improvement in endothelial function given its reported effects on increasing $\mathrm{NO}$ bioavailability, attributable, at least in part, to a reduction in ROS production. Strikingly, the addition of unspecific NO donor NTP, an endothelium-independent relaxant agent, induced similar vasodilation in WT and MFS aortae, suggesting that the VSMC-associated $\mathrm{NO} / \mathrm{sGC/cGMP}$ pathway is not altered. This result is seemingly in contrast to recently reported evidence using the same MFS mouse model, where an increase in plasma cGMP levels was reported (89). It is possible that the different age of the mice used in both studies may explain the difference and/or circulating cGMP appears not to be a consistently good indicator of SGC activity in MFS ascending aorta. Further studies are needed to clarify this point.

One other potential and complementary mechanism by which ALO reduces aortic wall disarray is through XDH-derived ROS activation of MPPs, since ROS are potent activators of MMPs (99). MMP2 and MMP9, two well-known MMPs involved in MFS aortopathy (100), can be indirectly activated by ROS from their inactivezymogen isoforms as well as via activation of their gene expression $(101,102)$. Likewise, it has been also reported that XDH itself can directly activate MMPs in a ROS-independent manner (103).

We are aware that our study has limitations: (i) unlike the ALO palliative treatment, the preventive approach followed in our study has no direct potential translational application to human patients because MFS is usually diagnosed during childhood or even later, unless MFS runs in the family. Only in that case, 
administering ALO might be considered during late pregnancy or after birth, some time before the aortic aneurysm might be expected to develop; (ii) some results only show a trend without reaching statistical significance, which most likely is a consequence of the habitual intrinsic high variability of results observed in MFS mice models. However, such clear trends do not necessarily invalidate these results and their potential pathophysiological significance; (iii) it cannot be discarded that ALO also mediates other XDH-independent actions such as the inhibition of heat shock protein expression (104), considering its significant role in MFS (105, 106); (iv) ALO has a short half-life in plasma and is rapidly metabolized to oxypurinol, which has a longer life-span (58)(107). It is possible that oxypurinol rather than allopurinol might be the primary metabolite that directly mediates the results we report here; $(\mathrm{v})$ the MFS model used in our study (C1041G) is a very useful model to evaluate the temporal course of aortopathy (besides other clinical manifestations), but it is not the most suitable to evaluate the survival rate after ALO treatments. Other more severe MFS murine models for aortic dissection and rupture, such as the Fbn 1 hypomorphic mouse (mgR/mgR) (108), or the previously mentioned Angll-induced accelerated model of MFS aortopathy (78), both leading to aortic dissection and rupture, should be more appropriate experimental murine models for this aim; and (vi) here we have only studied ALO's effects on the cardiovascular system (TAA more specifically), because it is responsible for the most life-threatening complications. Nevertheless, since MFS is a multisystemic disorder, it would also be important to study the putative effects of ALO on the other systems affected, even though it has been shown to be a safe and well-tolerated drug.

In conclusion, our results place redox stress among the molecular mechanisms that actively participate in the pathogenesis of aortic aneurysm in MFS by the consistent overproduction of ROS mediated by the overexpression of XDH (current study), the NADPH oxidases NOX4 (17) and NOX2 (78), the severe dysfunction of NOS (88), and mitochondria-associated redox stress (109), all being studies performed both in MFS murine models and patients. How, and to what extent, do each of these interlinked mechanisms participate in the aortic injury is currently unknown, but most likely they all act additively or synergistically to damage the aorta severely and permanently. Our results support the design of clinical trials based on well-characterized redox stress inhibitors, such as we report here for ALO. Importantly, ALO is a cheap drug, which is widely prescribed in clinical practice since

the latter half of the last century and, most importantly, is proven to be effective, safe, and well tolerated.

\section{MATERIAL AND METHODS}

A study design scheme is shown in Supplementary Figure 2.

All Materials and Methods used in this study are in Supplementary Materials.

\section{SUPPLEMENTARY MATERIALS}

Material and Methods section. 
Fig. S1. Reference positive control assay for the $\mathrm{XO}$ and $\mathrm{XDH}$ enzymatic activities performed in liver lysates.

Fig. S2. Representative scheme of the experimental protocols for allopurinol treatments.

Fig. S3. Uric acid and allantoin blood plasma levels are not altered in MFS mice.

Fig. S4. Allopurinol does not alter systolic blood pressure.

Fig. S5. XDH protein levels are not affected by allopurinol treatments.

Fig. S6. $\mathrm{H}_{2} \mathrm{O}_{2}$ plasma levels do not change with age in MFS mice.

Fig. S7. Preventive treatment with allopurinol does affect the collagen content and its maturation state in the media of MFS mice.

Fig. S8. Aortic root diameter measured by ultrasonography of 9-month-old WT and MFS mice palliatively treated or not with allopurinol for 24 weeks (PA2).

Table S1. Primers used in RT-PCR analysis in MFS mice.

Table S2. Aortic root diameter (in $\mathrm{mm}$ ) of WT and MFS mice subjected to palliative treatment (PA1) with allopurinol.

Table S3. Aortic root diameter (in $\mathrm{mm}$ ) of WT and MFS mice subjected to preventive treatment $(\mathrm{PE})$ with allopurinol.

Table S4. Aortic root diameter (in $\mathrm{mm}$ ) of WT and MFS mice subjected to palliative treatment (PA2) with allopurinol

Table S5. Potency (pEC50) and maximum response (Emax) of the concentrationresponse curves values for ACh- and NTP-induced relaxation response (\%) in the ascending aorta in the presence or absence of allopurinol.

Table S6. KCl vascular tone, potency, and maximum response of the concentrationresponse curve values for the Phe-induced contraction response in the ascending aorta in the presence or absence of allopurinol.

\section{REFERENCES AND NOTES}

1. H. C. Dietz, C. R. Cutting, R. E. Pyeritz, C. L. Maslen, L. Y. Sakai, G. M. Corson, E. G. Puffenberger, A. Hamosh, E. J. Nanthakumar, S. M. Curristin, G. Stetten, D. A. Meyers, C. A. Francomano, Marfan syndrome caused by a recurrent de novo missense mutation in the fibrillin gene. Nature. 352, 337339 (1991).

2. M. G. Keane, R. E. Pyeritz, Medical Management of Marfan Syndrome. Circulation. 117, 2802-13 (2008).

3. T. J. Costa, P. R. Barros, C. Arce, J. D. Santos, J. da Silva-Neto, G. Egea, A. P. Dantas, R. C. Tostes, F. Jiménez-Altayó, The homeostatic role of hydrogen peroxide, superoxide anion and nitric oxide in the vasculature. Free Radic. Biol. Med. 162, 314-9 (2021).

4. Q. Chen, Q. Wang, J. Zhu, Q. Xiao, L. Zhang, Reactive oxygen species: key regulators in vascular health and diseases, Br. J. Pharmacol. 175, 1279-1292 (2018). 
5. F. J. Miller, W. J. Sharp, X. Fang, L. W. Oberley, T. D. Oberley, N. L. Weintraub, Oxidative Stress in Human Abdominal Aortic Aneurysms. Arterioscler. Thromb. Vasc. Biol. 22, 560-5 (2002).

6. M. L. McCormick, D. Gavrila, N. L. Weintraub, Role of Oxidative Stress in the Pathogenesis of Abdominal Aortic Aneurysms. Arterioscler. Thromb. Vasc. Biol. 27, 461-9 (2007).

7. E. Papalambros, F. Sigala, S. Georgopoulos, K. I. Paraskevas, I. Andreadou, X. Menenakos, P. Sigalas, A. L. Papalambros, G. Vourliotakis, A. Giannopoulos, C. Bakoyiannis, E. Bastounis, Malondialdehyde as an Indicator of Oxidative Stress During Abdominal Aortic Aneurysm Repair. Angiology. 58, 477-82 (2007).

8. W. Xiong, J. Mactaggart, R. Knispel, J. Worth, Z. Zhu, Y. Li, Y. Sun, B. T. Baxter, J. Johanning, Inhibition of reactive oxygen species attenuates aneurysm formation in a murine model. Atherosclerosis 202, 128-34 (2009).

9. C. Aivatidi, G. Vourliotakis, S. Georgopoulos, F. Sigala, E. Bastounis, E. Papalambros, Oxidative stress during abdominal aortic aneurysm repair-biomarkers and antioxidant's protective effect: a review. Eur. Rev. Med. Pharmacol. Sci. 15, 245-52 (2011).

10. J. Pincemail, J. O. Defraigne, J. P. Cheramy-Bien, N. Dardenne, A. F. Donneau, A. Albert, N. Labropoulos, N. Sakalihasan, On the potential increase of the oxidative stress status in patients with abdominal aortic aneurysm. Redox Rep. 17, 139-44 (2012).

11. S. S. Portelli, B. D. Hambly, R. W. Jeremy, E. N. Robertson, Oxidative stress in genetically triggered thoracic aortic aneurysm: role in pathogenesis and therapeutic opportunities., Redox rep. 26, 45-52 (2021).

12.J. Ejiri, Oxidative stress in the pathogenesis of thoracic aortic aneurysm Protective role of statin and angiotensin II type 1 receptor blocker, Cardiovasc. Res. 59, 988-96 (2003).

13. C. Fiorillo, M. Becatti, M. Attanasio, L. Lucarini, N. Nassi, L. Evangelisti, M. C. Porciani, P. Nassi, G. F. Gensini, R. Abbate, G. Pepe, Evidence for oxidative stress in plasma of patients with Marfan syndrome. Int. J. Cardiol. 145, 544-6 (2010).

14. H. H. Yang, C. Van Breemen, A. W. Chung. Vasomotor dysfunction in the thoracic aorta of Marfan syndrome is associated with accumulation of oxidative stress. Vascul. Pharmacol. 52, 37-45 (2010).

15. E. Branchetti, P. Poggio, R. Sainger, E. Shang, J. B. Grau, B. M. Jackson, E. K. Lai, M. S. Parmacek, R. C. Gorman, J. H. Gorman, J. E. Bavaria, G. Ferrari, Oxidative stress modulates vascular smooth muscle cell phenotype via CTGF in thoracic aortic aneurysm, Cardiovasc. Res. 100, 316-24 (2013).

16. A. M. Zúñiga-Muñoz, I. Pérez-Torres, V. Guarner-Lans, E. Núñez-Garrido, R. Velázquez Espejel, C. Huesca-Gómez. R. Gamboa-Ávila, M. E. Soto. Glutathione system participation in thoracic aneurysms from patients with Marfan syndrome. Vasa. 46, 177-186 (2017). 
17.F. Jiménez-Altayó, T. Meirelles, E. Crosas-Molist, M. A. Sorolla, D. G. del Blanco, J. López-Luque, A. Mas-Stachurska, A.-M. Siegert, F. Bonorino, L. Barberà, C. García, E. Condom, M. Sitges, F. Rodríguez-Pascual, F. Laurindo, K. Schröder, J. Ros, I. Fabregat, G. Egea, Redox stress in Marfan syndrome: Dissecting the role of the NADPH oxidase NOX4 in aortic aneurysm. Free. Radic. Biol. Med. 118, 44-58 (2018).

18. F. Emrich, K. Penov, M. Arakawa, N. Dhablania, G. Burdon, A. J. Pedroza, T. K. Koyano, Y. M. Kim, U. Raaz, A. J. Connolly, C. losef, M. P. Fischbein, Anatomically specific reactive oxygen species production participates in Marfan syndrome aneurysm formation. J. Cell. Mol. Med. 23, 7000-7009 (2019).

19. G. Egea, F. Jiménez-Altayó, V. Campuzano, Reactive Oxygen Species and Oxidative Stress in the Pathogenesis and Progression of Genetic Diseases of the Connective Tissue. Antioxidants. 9, 1013 (2020).

20.J. Rysz, A. Gluba-Brzózka, R. Rokicki, B. Franczyk, Oxidative StressRelated Susceptibility to Aneurysm in Marfan's Syndrome. Biomedicines. 9, 1171 (2021).

21. J. Hewinson, C. R. Stevens, T. M. Millar, Vascular physiology and pathology of circulating xanthine oxidoreductase: from nucleotide sequence to functional enzyme. Redox Rep. 9, 71-9 (2004).

22. A. Boueiz, M. Damarla, P. M. Hassoun, Xanthine oxidoreductase in respiratory and cardiovascular disorders. Am. J. Physiol. Lung. Cell. Mol. Physiol. 294, L830-40 (2008).

23.M. G. Battelli, L. Polito, A. Bolognesi, Xanthine oxidoreductase in atherosclerosis pathogenesis: Not only oxidative stress. Atherosclerosis 237, 562-7 (2014).

24.J. L. McManaman, D. L. Bain, Structural and conformational analysis of the oxidase to dehydrogenase conversion of xanthine oxidoreductase., J. Biol. Chem. 277, 21261-8 (2002).

25. P. Pacher, A. Nivorozhkin, C. Szabó, Therapeutic Effects of Xanthine Oxidase Inhibitors: Renaissance Half a Century after the Discovery of Allopurinol. Pharmacol. Rev. 58, 87-114 (2006).

26. F. Lacy, D. A. Gough, G. W. Schmid-Schönbein, Role of xanthine oxidase in hydrogen peroxide production. Free. Radic. Biol. Med. 25, 720-7 (1998).

27. N. Cantu-Medellin, E. E. Kelley, Xanthine oxidoreductase-catalyzed reactive species generation: A process in critical need of reevaluation, Redox Biol. 1, 353-8 (2013).

28. C. R. White, V. Darley-Usmar, W. R. Berrington, M. McAdams, J. Z. Gore, J. A. Thompson, D. A. Parks, M. M. Tarpey, B. A. Freeman, Circulating plasma xanthine oxidase contributes to vascular dysfunction in hypercholesterolemic rabbits. Proc. Natl. Acad. Sci. USA. 93, 8745-9 (1996).

29. U. Landmesser, S. Spiekermann, S. Dikalov, H. Tatge, R. Wilke, C. Kohler, D. G. Harrison, B. Hornig, H. Drexler, Vascular Oxidative Stress and 
Endothelial Dysfunction in Patients With Chronic Heart Failure. Circulation 106, 3073-8 (2002).

30. H. M. Schmidt, E. E. Kelley, A. C. Straub, The impact of xanthine oxidase (XO) on hemolytic diseases. Redox Biol. 21, 101072 (2019).

31. H. C. Yang, J. M. Kim, E. Chum, C. van Breemen, A. W. Chung, Long-term effects of losartan on structure and function of the thoracic aorta in a mouse model of Marfan syndrome. Br. J. Pharmacol. 158, 37-45 (2009).

32. M. E. Soto, L. G. Manzano-Pech, V. Guarner-Lans, J. A. Díaz-Galindo, X. Vásquez, V. Castrejón-Tellez, R. Gamboa, C. Huesca, G. FuentevillaAlvárez, I. Pérez-Torres, Oxidant/Antioxidant Profile in the Thoracic Aneurysm of Patients with the Loeys-Dietz Syndrome. Oxid. Med. Cell. Longev. 2020, 5392454 (2020).

33. J. Maiuolo, F. Oppedisano, S. Gratteri, C. Muscoli, V. Mollace, Regulation of uric acid metabolism and excretion. Int. J. Cardiol. 213, 8-14 (2016).

34. W. Doehner, N. Schoene, M. Rauchhaus, F. Leyva-Leon, D. v. Pavitt, D. A. Reaveley, G. Schuler, A. J. S. Coats, S. D. Anker, R. Hambrecht, Effects of Xanthine Oxidase Inhibition With Allopurinol on Endothelial Function and Peripheral Blood Flow in Hyperuricemic Patients With Chronic Heart Failure. Circulation. 105, 2619-24 (2002).

35. R. Kand'ár, P. Žáková, V. Mužáková, Monitoring of antioxidant properties of uric acid in humans for a consideration measuring of levels of allantoin in plasma by liquid chromatography. Clin. Chim. Acta. 365, 249-56 (2006).

36. M. Kanbay, M. Segal, B. Afsar, D.-H. Kang, B. Rodriguez-lturbe, R. J. Johnson, The role of uric acid in the pathogenesis of human cardiovascular disease. Heart. 99,759-66 (2013).

37. C. Vassalle, A. Mazzone, L. Sabatino, C. Carpeggiani, Uric Acid for Cardiovascular Risk: Dr. Jekyll or Mr. Hide? Diseases 4, 12 (2016).

38. G. Glantzounis, E. Tsimoyiannis, A. Kappas, D. Galaris, Uric Acid and Oxidative Stress. Curr. Pharm. Des. 11, 4145-51 (2005).

39. D.-H. Kang, S.-K. Ha, Uric Acid Puzzle: Dual Role as Anti-oxidantand Prooxidant. Electrolyte. Blood. Press. 12, 1-6 (2014).

40. D. B. Corry, P. Eslami, K. Yamamoto, M. D. Nyby, H. Makino, M. L. Tuck, Uric acid stimulates vascular smooth muscle cell proliferation and oxidative stress via the vascular renin-angiotensin system, J. Hypertens. 26, 269-75 (2008).

41. M. A. Yu, L. G. Sánchez-Lozada. R. J. Johnson, D. H. Kang. Oxidative stress with an activation of the renin-angiotensin system in human vascular endothelial cells as a novel mechanism of uric acid-induced endothelial dysfunction. J. Hypertens. 28, 1234-42 (2010).

42. P. Patetsios, W. Rodino, W. Wisselink, D. Bryan, J. D. Kirwin, T. F. Panetta, Identification of Uric Acid in Aortic Aneurysms and Atherosclerotic Artery. Ann. N. Y. Acad. Sci. 800, 243-5 (1996). 
43. A. M. Esen, M. Akcakoyun, O. Esen, G. Acar, Y. Emiroglu, S. Pala, R. Kargin, H. Karapinar, O. Ozcan, I. Barutcu, Uric Acid as a Marker of Oxidative Stress in Dilatation of the Ascending Aorta. Am. J. Hypertens. 24, 149-54 (2011).

44.W.-L. Jiang, X. Qi, X. Li, Y.-F. Zhang, Q.-Q. Xia, J.-C. Chen, Serum uric acid is associated with aortic dissection in Chinese men. Int. J. Cardiol. 202, 1967 (2016).

45. J. Cai, Y. Zhang, J. Zou, Y. Shen, D. Luo, H. Bao, Y. Chen, J. Ye, J. Guan, Serum uric acid could be served as an independent marker for increased risk and severity of ascending aortic dilatation in Behçet's disease patients. J. Clin. Lab. Anal. 33,22637 (2019).

46. M. Houston, P. Chumley, R. Radi, H. Rubbo, B. A. Freeman, Xanthine Oxidase Reaction with Nitric Oxide and Peroxynitrite. Arch. Biochem. Biophys. 355, 1-8 (1998).

47. H. Ischiropoulos, Biological Tyrosine Nitration: A Pathophysiological Function of Nitric Oxide and Reactive Oxygen Species. Arch. Biochem. Biophys. 356, 1-11 (1998).

48. G. Ndrepepa, Uric acid and cardiovascular disease. Clinica Chimica Acta 484, 150-163 (2018).

49. K. Huang, Y. Wang, K. L. Siu, Y. Zhang, H. Cai, Targeting feed-forward signaling of TGF $\beta / N O X 4 / D H F R / e N O S$ uncoupling/TGF $\beta$ axis with anti-TGF $\beta$ and folic acid attenuates formation of aortic aneurysms: Novel mechanisms and therapeutics. Redox. Biol. 38, 101757 (2021).

50. A. Kelkar, A. Kuo, W. H. Frishman, Allopurinol as a Cardiovascular Drug, Cardiol. Rev. 19, 265-71 (2011).

51. C. Arce, I. Rodríguez-Rovira, K. de Rycke, K. Durán, V. Campuzano, I. Fabregat, F. Jiménez-Altayó, P. Berraondo, G. Egea, Anti-TGF $\beta$ (Transforming Growth Factor $\beta$ ) Therapy With Betaglycan-Derived P144 Peptide Gene Delivery Prevents the Formation of Aortic Aneurysm in a Mouse Model of Marfan Syndrome. Arterioscler. Thromb. Vasc. Biol. 41, e440-e452 (2021).

52. Y. Amaya, K. Yamazaki, M. Sato, K. Noda, T. Nishino, T. Nishino, Proteolytic conversion of xanthine dehydrogenase from the NAD-dependent type to the O2-dependent type. Amino acid sequence of rat liver xanthine dehydrogenase and identification of the cleavage sites of the enzyme protein during irreversible conversion by trypsin. J. Biol. Chem. 265, 14170-5 (1990).

53. X. W. Qu, R. A. Rozenfeld, W. Huang, G. B. Bulkley, W. Hsueh, The role of xanthine oxidase in platelet activating factor induced intestinal injury in the rat., Gut 44, 203-11 (1999).

54. U. S. Kayyali, C. Donaldson, H. Huang, R. Abdelnour, P. M. Hassoun, Phosphorylation of Xanthine Dehydrogenase/Oxidase in Hypoxia. J. Biol. Chem. 276, 14359-65 (2001). 
55. W. Gwinner, H. Scheuer, H. Haller, R. P. Brandes, H.-J. Groene, Pivotal role of xanthine oxidase in the initiation of tubulointerstitial renal injury in rats with hyperlipidemia., Kidney Int. 69, 481-7 (2006).

56. J. S. Beckman, D. A. Parks, J. D. Pearson, P. A. Marshall, B. A. Freeman, A sensitive fluorometric assay for measuring xanthine dehydrogenase and oxidase in tissues. Free Radic. Biol. Med. 6, 607-15 (1989).

57. H. C. Yang, J. M. Kim, E. Chum, C. van Breemen, A. W. Chung, Long-term effects of losartan on structure and function of the thoracic aorta in a mouse model of Marfan syndrome. Br. J. Pharmacol. 158, 37-45 (2010).

58. R. O. Day, G. G. Graham, M. Hicks, A. J. McLachlan, S. L. Stocker, K. M. Williams, Clinical Pharmacokinetics and Pharmacodynamics of Allopurinol and Oxypurinol. Clin. Pharmacokinet. 46, 623-44 (2007).

59. N. Masaoka, Y. Nakajima, Y. Hayakawa, S. Ohgame, S. Hamano, M. Nagaishi, T. Yamamoto, Transplacental effects of allopurinol on suppression of oxygen free radical production in chronically instrumented fetal lamb brains during intermittent umbilical cord occlusion. J. Matern. Fetal. Neonatal. Med. 18, 1-7 (2005).

60. H. L. Torrance, M. J. Benders, J. B. Derks, C. M. A. Rademaker, A. F. Bos, P. van den Berg, M. Longini, G. Buonocore, M. Venegas, H. Baquero, G. H. A. Visser, F. van Bel, Maternal Allopurinol During Fetal Hypoxia Lowers Cord Blood Levels of the Brain Injury Marker S-100B. Pediatrics. 124, 350-7 (2009).

61.J. B. Derks, M. A. Oudijk, H. L. Torrance, C. Rademaker, M. J. Benders, K. G. Rosen, T. Cindrova-Davies, A. S. Thakor, G. H. A. Visser, G. J. Burton, F. van Bel, D. A. Giussani, Allopurinol Reduces Oxidative Stress in the Ovine Fetal Cardiovascular System Following Repeated Episodes of IschemiaReperfusion. Pediatr. Res. 5, 374-80 (2010).

62. Y. Niu, A. D. Kane, C. M. Lusby, B. J. Allison, Y. Y. Chua, J. J. Kaandorp, R. Nevin-Dolan, T. J. Ashmore, H. L. Blackmore, J. B. Derks, S. E. Ozanne, D. A. Giussani, Maternal Allopurinol Prevents Cardiac Dysfunction in Adult Male Offspring Programmed by Chronic Hypoxia During Pregnancy. Hypertension 72, 971-978 (2018).

63. J. W. Wisler, E. M. Harris, M. Raisch, L. Mao, J. Kim, H. A. Rockman, R. J. Lefkowitz, the role of $\beta$-arrestin2-dependent signaling in thoracic aortic aneurysm formation in a murine model of Marfan syndrome., Am. J. Physiol. Heart Circ. Physiol. 309, 1516-27 (2015).

64. H. Y. Chung, B. S. Baek, S. H. Song, M. S. Kim, J. I. Huh, K. H. Shim, K. W. Kim, K. H. Lee, Xanthine dehydrogenase/xanthine oxidase and oxidative stress, AGE 20, 127-40 (1997).

65.B. W. Stein, M. L. Kirk, Electronic structure contributions to reactivity in xanthine oxidase family enzymes, J. Biol. Inorg. Chem. 20 (2015).

66. R. Hille, V. Massey, Studies on the oxidative half-reaction of xanthine oxidase. J. Biol. Chem. 256, 9090-5 (1981). 
67. E. E. Kelley, N. K. H. Khoo, N. J. Hundley, U. Z. Malik, B. A. Freeman, M. M. Tarpey, Hydrogen peroxide is the major oxidant product of xanthine oxidase. Free. Radic. Biol. Med. 48, 493-8 (2010).

68. M. Ichinose, H. Sugiura, S. Yamagata, A. Koarai, M. Tomaki, H. Ogawa, Y. Komaki, P. J. Barnes, K. Shirato, T. Hattori, Xanthine oxidase inhibition reduces reactive nitrogen species production in COPD airways. Eur. Respir. J. 22, 457-61 (2003).

69. T. Nguyen, H. C. Huang, C. B. Pickett, Transcriptional Regulation of the Antioxidant Response Element. J. Biol. Chem. 275, 15466-73 (2000).

70. Q. Ma, Role of Nrf2 in Oxidative Stress and Toxicity. Annu. Rev. Pharmacol. Toxicol. 53, 401-26 (2013).

71. J. H. N. Lindeman, B. A. Ashcroft, J.-W. M. Beenakker, M. van Es, N. B. R. Koekkoek, F. A. Prins, J. F. Tielemans, H. Abdul-Hussien, R. A. Bank, T. H. Oosterkamp, Distinct defects in collagen microarchitecture underlie vesselwall failure in advanced abdominal aneurysms and aneurysms in Marfan syndrome, Proc. Natl. Acad. Sci. USA 107, 862-5 (2010).

72. O. Busnadiego, D. Gorbenko del Blanco, J. González-Santamaría, J. P. Habashi, J. F. Calderon, P. Sandoval, D. Bedja, J. Guinea-Viniegra, M. Lopez-Cabrera, T. Rosell-Garcia, J. M. Snabel, R. Hanemaaijer, A. Forteza, H. C. Dietz, G. Egea, F. Rodriguez-Pascual, Elevated expression levels of lysyl oxidases protect against aortic aneurysm progression in Marfan syndrome, J. Mol. Cell. Cardiol. 85, 48-57 (2015).

73. J. López-Guimet, L. Peña-Pérez, R. S. Bradley, P. García-Canadilla, C. Disney, H. Geng, A. J. Bodey, P. J. Withers, B. Bijnens, M. J. Sherratt, G. Egea, MicroCT imaging reveals differential 3D micro-scale remodelling of the murine aorta in ageing and Marfan syndrome. Theranostics. 8, 6038-6052 (2018).

74. L. Rittié. Method for Picrosirius Red-Polarization Detection of Collagen Fibers in Tissue Sections. Methods Mol Biol 1627, 395-407 (2017).

75. E. E. Kelley, A new paradigm for XOR-catalyzed reactive species generation in the endothelium. Pharmacol. Rep. 67, 669-74 (2015).

76. A. W. Y. Chung, K. Au Yeung, S. F. Cortes, G. G. S. Sandor, D. P. Judge, H. C. Dietz, C. van Breemen, Endothelial dysfunction and compromised eNOS/Akt signaling in the thoracic aorta during the progression of Marfan syndrome, Br. J.I Pharmacol. 150, 1075-83 (2007).

77. F. Jiménez-Altayó, A.-M. Siegert, F. Bonorino, T. Meirelles, L. Barberà, A. P. Dantas, E. Vila, G. Egea, Differences in the Thoracic Aorta by Region and Sex in a Murine Model of Marfan Syndrome., Front. Physiol. 8, 933 (2017).

78. F. S. Nettersheim, J. Lemties, S. Braumann, S. Geißen, S. Bokredenghel, R. Nies, A. Hof, H. Winkels, B. A. Freeman, A. Klinke, V. Rudolph, S. Baldus, D. Mehrkens, M. Mollenhauer, M. Adam, Nitro-oleic acid (NO2-OA) reduces thoracic aortic aneurysm progression in a mouse model of Marfan syndrome., Cardiovasc. Res. (2021). 
79. O. N. Okafor, K. Farrington, D. A. Gorog, Allopurinol as a therapeutic option in cardiovascular disease. Pharmacol. Ther. 172, 139-150 (2017).

80. C. Chen, J.-M. Lü, Q. Yao, Hyperuricemia-Related Diseases and Xanthine Oxidoreductase (XOR) Inhibitors: An Overview, Med. Sci. Monit. 22, 2501-12 (2016).

81. M. Bove, A. F. G. Cicero, M. Veronesi, C. Borghi, An evidence-based review on urate-lowering treatments: implications for optimal treatment of chronic hyperuricemia. Vasc. Health Risk. Manag. 13, 23-28 (2017).

82. D. K. Das, R. M. Engelman, R. Clement, H. Otani, M. R. Prasad, P. S. Rao, Role of xanthine oxidase inhibitor as free radical scavenger: A novel mechanism of action of allopurinol and oxypurinol in myocardial salvatge. Biochem. Biophys. Res. Commun. 148, 314-9 (1987).

83. J. George, Role of urate, xanthine oxidase and the effects of allopurinol in vascular oxidative stress. Vasc. Health. Risk. Manag. 5, 265-72 (2009).

84. M. Yamaguchi, K. Okamoto, T. Kusano, Y. Matsuda, G. Suzuki, A. Fuse, H. Yokota, The Effects of Xanthine Oxidoreductase Inhibitors on Oxidative Stress Markers following Global Brain Ischemia Reperfusion Injury in C57BL/6 Mice. PLOS ONE 10, e0133980 (2015).

85. R. C. Nogueira, L. C. Pinheiro, J. M. Sanches-Lopes, J. M. Parente, G. H. Oliveira-Paula, S. O. Conde, M. M. Castro, J. E. Tanus-Santos, Omeprazole induces vascular remodeling by mechanisms involving xanthine oxidoreductase and matrix metalloproteinase activation., Biochem Pharmacol. 190, 114633 (2021).

86. H. Otani, The Role of Nitric Oxide in Myocardial Repair and Remodeling, Antioxid. Redox. Signal. 11, 1913-28 (2009).

87. R. Radi, Protein tyrosine nitration: biochemical mechanisms and structural basis of functional effects., Acc. Chem. Res. 46, 550-9 (2013).

88. J. Oller, N. Méndez-Barbero, E. J. Ruiz, S. Villahoz, M. Renard, L. I. Canelas, A. M. Briones, R. Alberca, N. Lozano-Vidal, M. A. Hurlé, D. Milewicz, A. Evangelista, M. Salaices, J. F. Nistal, L. J. Jiménez-Borreguero, J. de Backer, M. R. Campanero, J. M. Redondo, Nitric oxide mediates aortic disease in mice deficient in the metalloprotease Adamts1 and in a mouse model of Marfan syndrome, Nat. Med. 23, 200-212 (2017).

89. A. de la Fuente-Alonso, M. Toral, A. Alfayate, M. J. Ruiz-Rodríguez, E. Bonzón-Kulichenko, G. Teixido-Tura, S. Martínez-Martínez, M. J. MéndezOlivares, D. López-Maderuelo, I. González-Valdés, E. Garcia-Izquierdo, S. Mingo, C. E. Martín, L. Muiño-Mosquera, J. de Backer, J. F. Nistal, A. Forteza, A. Evangelista, J. Vázquez, M. R. Campanero, J. M. Redondo, Aortic disease in Marfan syndrome is caused by overactivation of SGC-PRKG signaling by NO. Nat. Commun. 12, 2628 (2021).

90. D. M. Milewicz, D.-C. Guo, V. Tran-Fadulu, A. L. Lafont, C. L. Papke, S. Inamoto, C. S. Kwartler, H. Pannu, Genetic Basis of Thoracic Aortic 
Aneurysms and Dissections: Focus on Smooth Muscle Cell Contractile Dysfunction. Annu. Rev. Genomics. Hum. Genet. 9, 283-302 (2008).

91. P. Nolasco, C. G. Fernandes, J. C. Ribeiro-Silva, P. V. S. Oliveira, M. Sacrini, I. V. de Brito, T. C. de Bessa, L. v. Pereira, L. Y. Tanaka, A. Alencar, F. R. M. Laurindo, Impaired vascular smooth muscle cell force-generating capacity and phenotypic deregulation in Marfan Syndrome mica. Biochim. Biophys. Acta. Mol. Basis. Dis. 1866, 1665587 (2020).

92. N. Robledinos-Antón, R. Fernández-Ginés, G. Manda, A. Cuadrado, Activators and Inhibitors of NRF2: A Review of Their Potential for Clinical Development. Oxid Med Cell Longev. (2019).

93. F. He, X. Ru, T. Wen, NRF2, a Transcription Factor for Stress Response and Beyond. Int. J. Mol. Sci. 21, 4777 (2020).

94. X. Ju, T. ljaz, H. Sun, W. LeJeune, G. Vargas, T. Shilagard, A. Recinos, D. M. Milewicz, A. R. Brasier, R. G. Tilton, IL-6 Regulates Extracellular Matrix Remodeling Associated With Aortic Dilation in a Fibrillin-1 Hypomorphic $\mathrm{mgR} / \mathrm{mgR}$ Mouse Model of Severe Marfan Syndrome. J. Am. Heart. Assoc. 3, e000476 (2014).

95. A. J. Pedroza, Y. Tashima, R. Shad, P. Cheng, R. Wirka, S. Churovich, K. Nakamura, N. Yokoyama, J. Z. Cui, C. losef, W. Hiesinger, T. Quertermous, M. P. Fischbein, Single-Cell Transcriptomic Profiling of Vascular Smooth Muscle Cell Phenotype Modulation in Marfan Syndrome Aortic Aneurysm. Arterioscler. Thromb. Vasc. Biol. 40, 2195-2211 (2020).

96. E. Crosas-Molist, T. Meirelles, J. López-Luque, C. Serra-Peinado, J. Selva, L. Caja, D. Gorbenko del Blanco, J. J. Uriarte, E. Bertran, Y. Mendizábal, V. Hernández, C. García-Calero, O. Busnadiego, E. Condom, D. Toral, M. Castellà, A. Forteza, D. Navajas, E. Sarri, F. Rodríguez-Pascual, H. C. Dietz, I. Fabregat, G. Egea, Vascular Smooth Muscle Cell Phenotypic Changes in Patients With Marfan Syndrome. Arterioscler. Thromb. Vasc. Biol. 35, 960-72 (2015).

97. Y. Hellsten, in Handbook of Oxidants and Antioxidants in Exercise, (Elsevier, 2000).

98. M. G. Battelli, L. Polito, M. Bortolotti, A Bolognesi, Xanthine OxidoreductaseDerived Reactive Species: Physiological and Pathological Effects. Oxid. Med. Cell. Longev. 2016, 3527579 (2016).

99. L. A. Martínez-Lemus, E. L. Galiñanes, Matrix metalloproteinases and small artery remodeling, Drug Discov. Today Dis. Models. 8, 21-28 (2011).

100. A. Y. Tehrani, J. Z. Cui, T. Bucky Jones, E. Hotova, M. Castro, P. Bernatchez, C. van Breemen, M. Esfandiarei, Characterization of doxycycline-mediated inhibition of Marfan syndrome-associated aortic dilation by multiphoton microscopy, Sci. Rep. 10, 7154 (2020).

101. S. Rajagopalan, X. P. Meng, S. Ramasamy, D. G. Harrison, Z. S. Galis, Reactive oxygen species produced by macrophage-derived foam cells regulate the activity of vascular matrix metalloproteinases in vitro. 
Implications for atherosclerotic plaque stability., J. Clin. Invest. 98,2572-9 (1996).

102. F. Valentin, J.-L. Bueb, P. Kieffer, E. Tschirhart, J. Atkinson, Oxidative stress activates MMP-2 in cultured human coronary smooth muscle cells., Fundam. Clin. Pharmacol. 19, 661-7 (2005).

103. W. Liu, G. A. Rosenberg, H. Shi, T. Furuichi, G. S. Timmins, L. A. Cunningham, K. J. Liu, Xanthine oxidase activates pro-matrix metalloproteinase-2 in cultured rat vascular smooth muscle cells through nonfree radical mechanisms., Arch. Biochem. Biophys. 426, 11-7 (2004).

104. J. Nishizawa, A. Nakai, K. Matsuda, M. Komeda, T. Ban, K. Nagata, Reactive Oxygen Species Play an Important Role in the Activation of Heat Shock Factor 1 in Ischemic-Reperfused Heart. Circulation 99, 934-41 (1999). 105. T. Meirelles, T. L. S. Araujo, P. Nolasco, A. I. S. Moretti, M. C. Guido, V. Debbas, L. v. Pereira, F. R. Laurindo, Fibrillin-1 mg $\Delta$ lpn Marfan syndrome mutation associates with preserved proteostasis and bypass of a protein disulfide isomerase-dependent quality checkpoint. Int. J. Biochem. Cell. Biol. 71, 81-91 (2016).

106. A.-M. Siegert, G. García Díaz-Barriga, A. Esteve-Codina, M. NavasMadroñal, D. Gorbenko del Blanco, J. Alberch, S. Heath, M. Galán, G. Egea, A FBN1 3'UTR mutation variant is associated with endoplasmic reticulum stress in aortic aneurysm in Marfan syndrome. Biochim. Biophys. Acta. Mol. Basis. Dis. 1865, 107-114 (2019).

107. F. Pea, Pharmacology of drugs for hyperuricemia. Mechanisms, kinetics and interactions. Contrib. Nephrol. 147, 35-46 (2005).

108. L. Pereira, S. Y. Lee, B. Gayraud, K. Andrikopoulos, S. D. Shapiro, T. Bunton, N. J. Biery, H. C. Dietz, L. Y. Sakai, F. Ramirez, Pathogenetic sequence for aneurysm revealed in mice underexpressing fibrillin-1., Proc Natl Acad Sci U S A 96, 3819-23 (1999).

109. J. Oller, E. Gabandé-Rodríguez, M. J. Ruiz-Rodríguez, G. DesdínMicó, J. F. Aranda, R. Rodrigues-Diez, C. Ballesteros-Martínez, E. M. Blanco, R. Roldan-Montero, P. Acuña, A. Forteza Gil, C. E. Martín-López, J. F. Nistal, C. L. Lino Cardenas, M. E. Lindsay, J. L. Martín-Ventura, A. M. Briones, J. Miguel Redondo, M. Mittelbrunn, Extracellular Tuning of Mitochondrial Respiration Leads to Aortic Aneurysm. Circulation 143, 2091-2109 (2021).

Acknowledgements: We thank Isabel Fabregat and Hal Dietz for critically reading the manuscript, Ana Paula Dantas for helpful methodological advice with $\mathrm{H}_{2} \mathrm{O}_{2}$ fluorometric measurements, Helena Kruyer for editorial assistance and Maite Muñoz for lab management.

Funding: This work was supported by:

Poorly endowed Spanish Ministry of Innovation and Science government grant PID2020-113634RB-C2 to GE and FJ-A. 


\section{Author contributions:}

Conceptualization: FJ-A, GE

Methodology: IR-R, CA, KdR, BP-F, AC, MA, FJ-A

Investigation: IR-R, CA, KdR, BP-F, AC, MA, VC, FJ-A, GE

Funding acquisition: $F G-A$ and $G E$

Supervision: GT-T, VC, MCG-C, FJ-A, GE

Writing - original draft: GE

Writing - review \& editing: all authors

Competing interests: Authors declare that they have no competing interests

Data and materials availability: All data are available in the main text or the supplementary materials 
FIGURES AND FIGURE LEGENDS
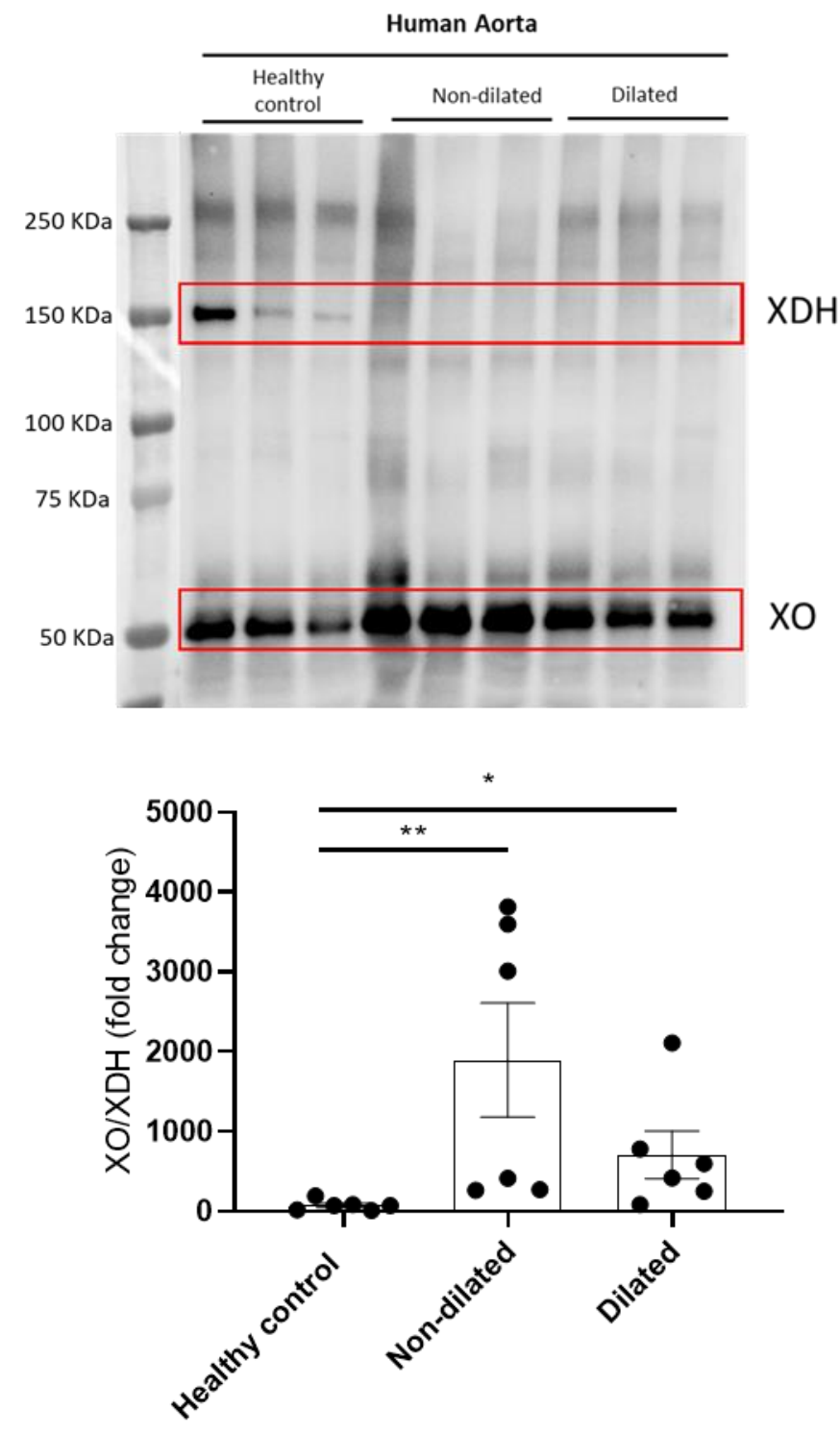

Figure 1. The Xanthine oxidase (XO) protein form is increased in the aortic aneurysm of MFS patients. XDH and XO protein forms of XOR revealed by western blotting in the dilated and immediately adjacent non-dilated aneurysm zone of the aorta from Marfan patients subjected to aortic surgery and from healthy controls. The ratio between $\mathrm{XO} / \mathrm{XDH}$ protein bands is shown. Statistical test analysis: KruskalWallis and Dunn's post-test, ${ }^{* \star} P \leq 0.01$. Number of samples analyzed: 6 . 
A

3 months

6 months
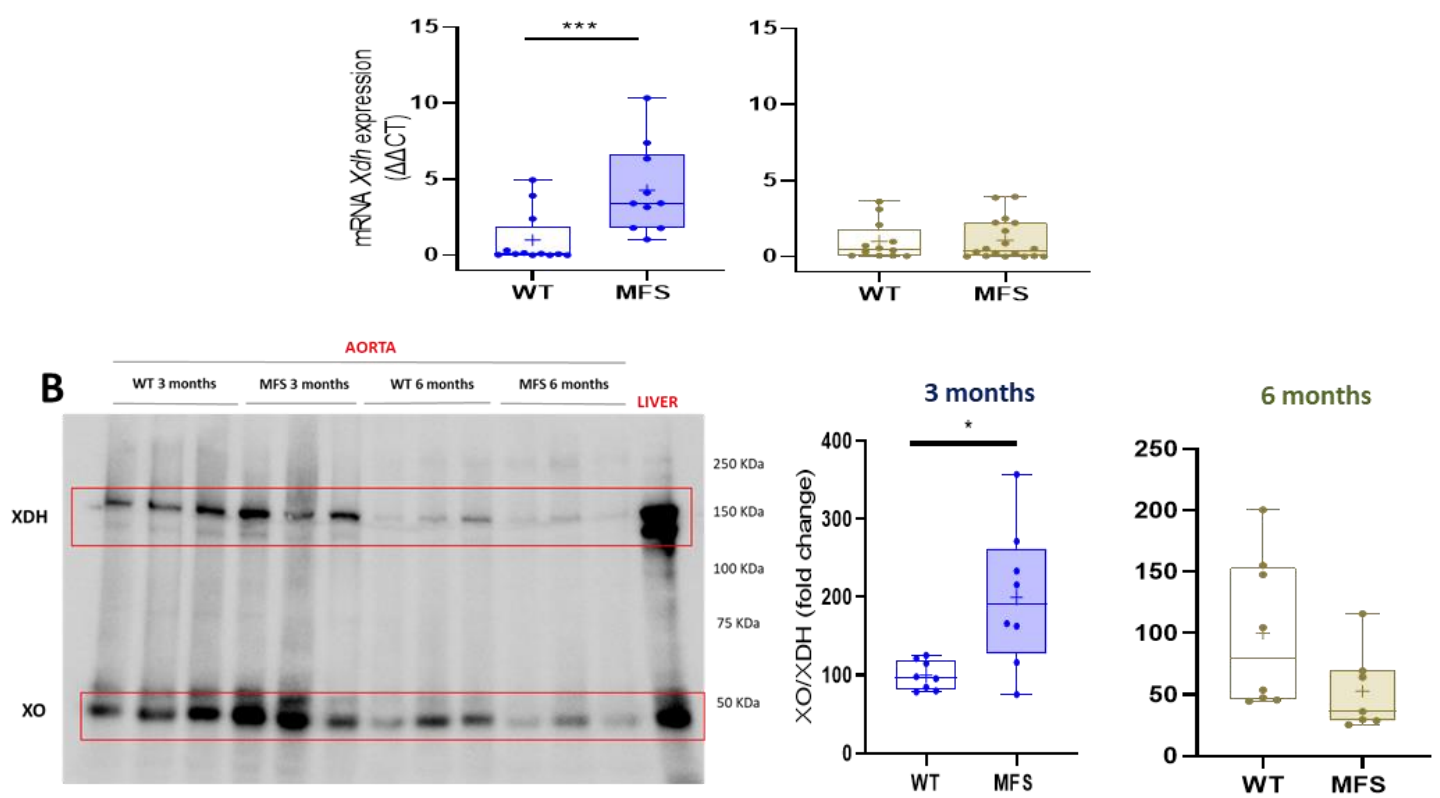

C

WT

MFS
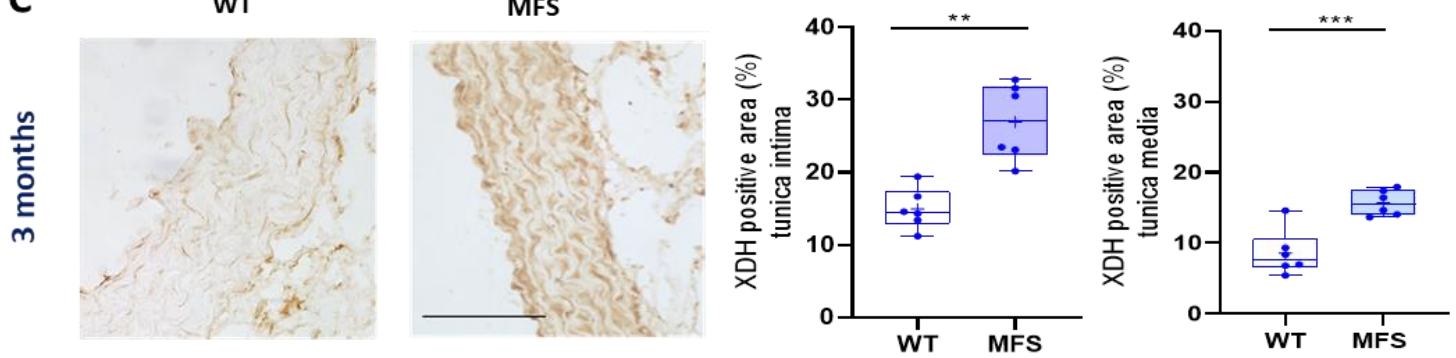

D
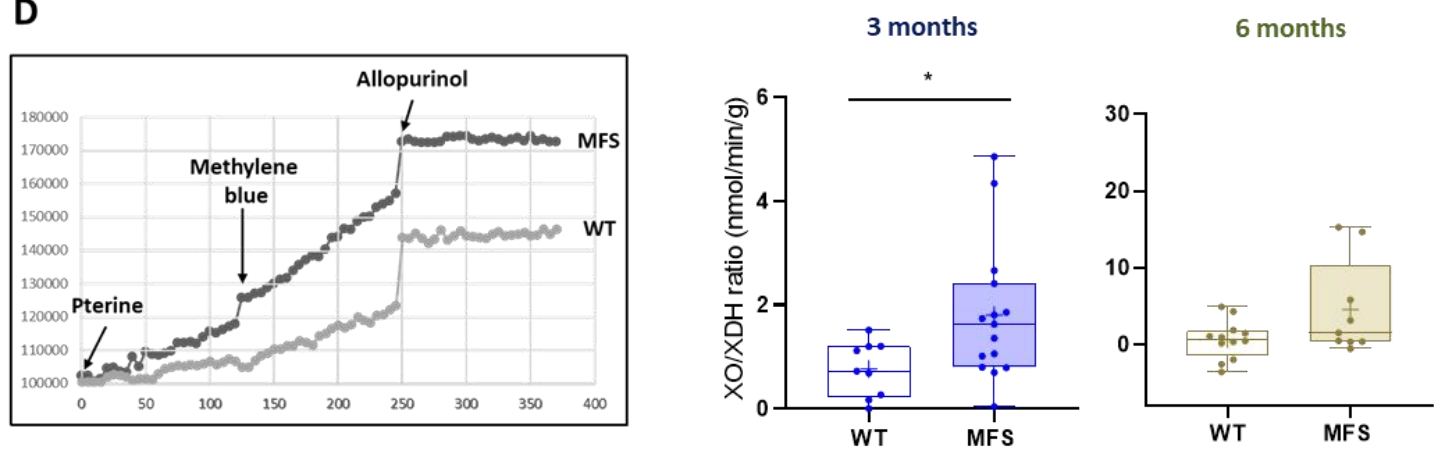

Figure 2. Xanthine dehydrogenase (XDH) mRNA expression levels, and xanthine oxidase $(X O)$ protein formation and enzymatic activity are increased in MFS mice ascending aorta. (A) mRNA expression levels of XOR/XDH in WT and MFS mice of different ages ( 3 and 6 months-old). (B) XDH and XO protein bands revealed by western blotting in WT and MFS aorta of 3- and 6-month-old mice. The ratio between $\mathrm{XO} / \mathrm{XDH}$ protein bands is also shown. (C) $\mathrm{XDH}$ expression levels revealed by immunohistochemistry in paraffin-embedded aortae from 3-month-old WT and MFS mice. On the right, quantitative analysis of the respective HRP 
immunostaining in tunicae intima and media. Bar, $100 \mu \mathrm{m}$. (D) Representative assay for $\mathrm{XO}$ and $\mathrm{XDH}$ enzymatic activity forms (on the left) and the $\mathrm{XO} / \mathrm{XDH}$ ratio in WT and 3- and 6-month-old MFS mice (on the right). A representative positive control assay performed in liver lysates is shown in supplemental figure 1. Statistical test analysis: (A and B) Kruskal-Wallis followed by Bonferroni post-hoc tests; (C) Mann Whitney $U$ test; (D) Mann Whitney test for both WT/MFS mice ages. ${ }^{* * *} p \leq 0.001$, ${ }^{* *} p \leq 0.01$, and ${ }^{*} p \leq 0.05$. Number of animals used 10-15 (A), 7-8 (B), 5 (C) and 8-12 (D). 


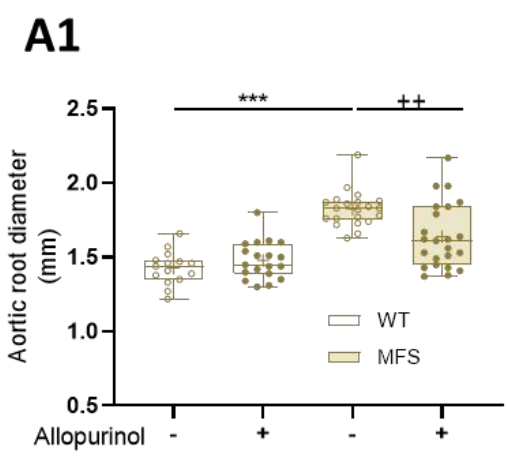

\section{A2}
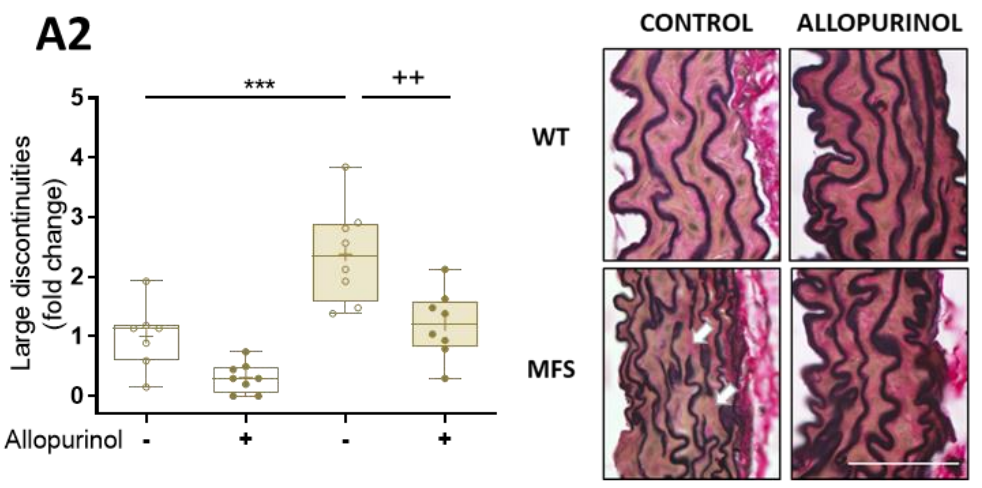

B1

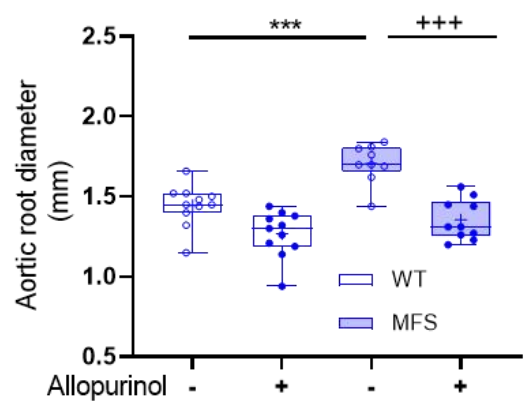

B2
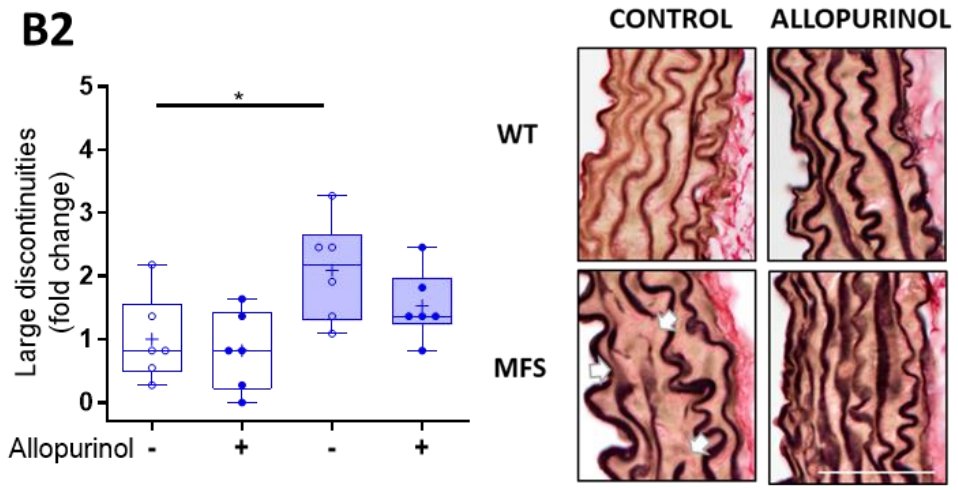

Figure 3. Allopurinol prevents the formation and progression of aortic root dilation in MFS mice. (A1) Allopurinol halts the progression of aortic root dilatation in MFS mice, measured by ultrasonography in WT and MFS mice of 6 months of age treated with allopurinol for 16 weeks (PA1). For specific values, see supplemental Table 2. (A2) The number of large discontinuities in the elastic lamina of the tunica media of the ascending aorta (360) from WT and MFS mice palliatively treated with allopurinol. On the right, representative elastin histological staining (Elastin Verhoeff-Van Gieson) in paraffin sections of the ascending aorta. Bar, 100 $\mu \mathrm{m}$. (B1) Allopurinol prevents the formation of aortic root dilatation in MFS mice measured by 2D echocardiography in 3-month-old WT and MFS mice preventively treated (PE) with allopurinol for 12 weeks. For specific values, see supplemental Table 3. (B2) Number of large discontinuities in the elastic lamina of the tunica media of the ascending aorta $\left(360^{\circ}\right)$ from WT and MFS mice preventively treated with allopurinol. On the right, representative elastin histological staining (Elastin VerhoeffVan Gieson) in paraffin sections of the ascending aorta. White arrows in A2 and B2 indicate representative examples of the large discontinuities analyzed. Bar, $100 \mu \mathrm{m}$. Statistical analysis: Two-way ANOVA and Tukey post-test (A and B). ${ }^{* * *+++} P \leq 0.001$, ${ }^{++} P \leq 0.01$ and ${ }^{*} P \leq 0.05$; "significance between genotype; 'significance between treatments. Number of animals analyzed: 14-16 (PA1) and 9-11 (PE). 


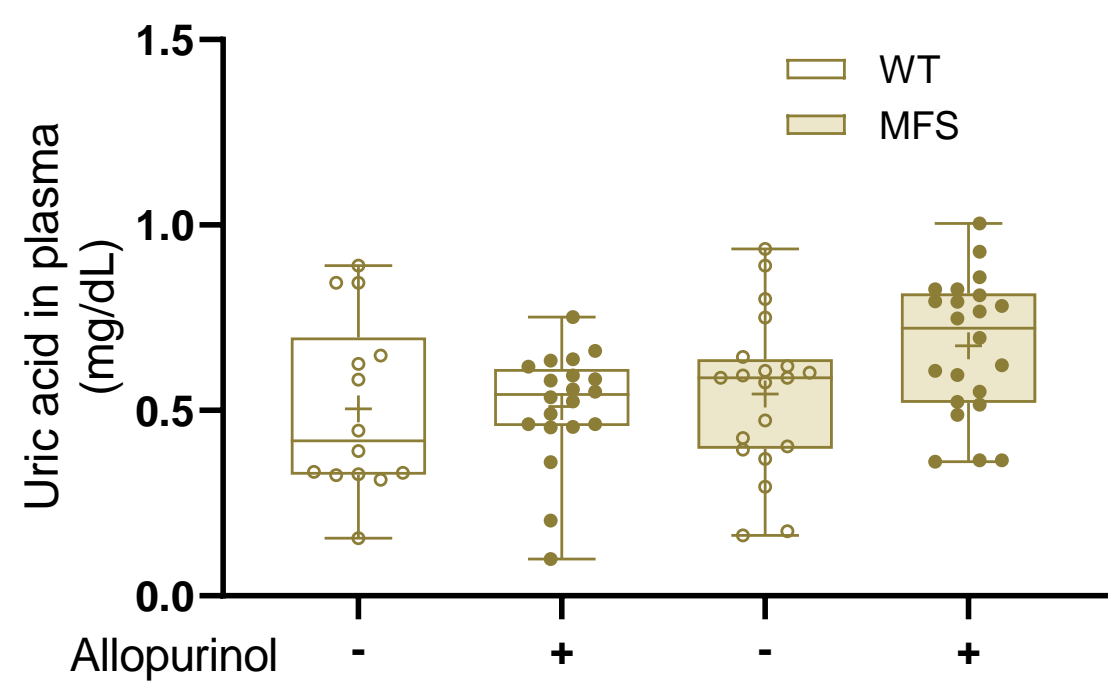

Figure 4. Allopurinol does not affect uric acid levels regardless of genotype. Uric acid blood plasma levels in WT and MFS mice palliatively treated or not with allopurinol for 16 weeks (PA1). Allopurinol does not affect UA plasma levels both in WT and MFS mice. Statistical analysis: Two-way ANOVA and Tukey post-test. Number of samples analyzed: 14-22. 


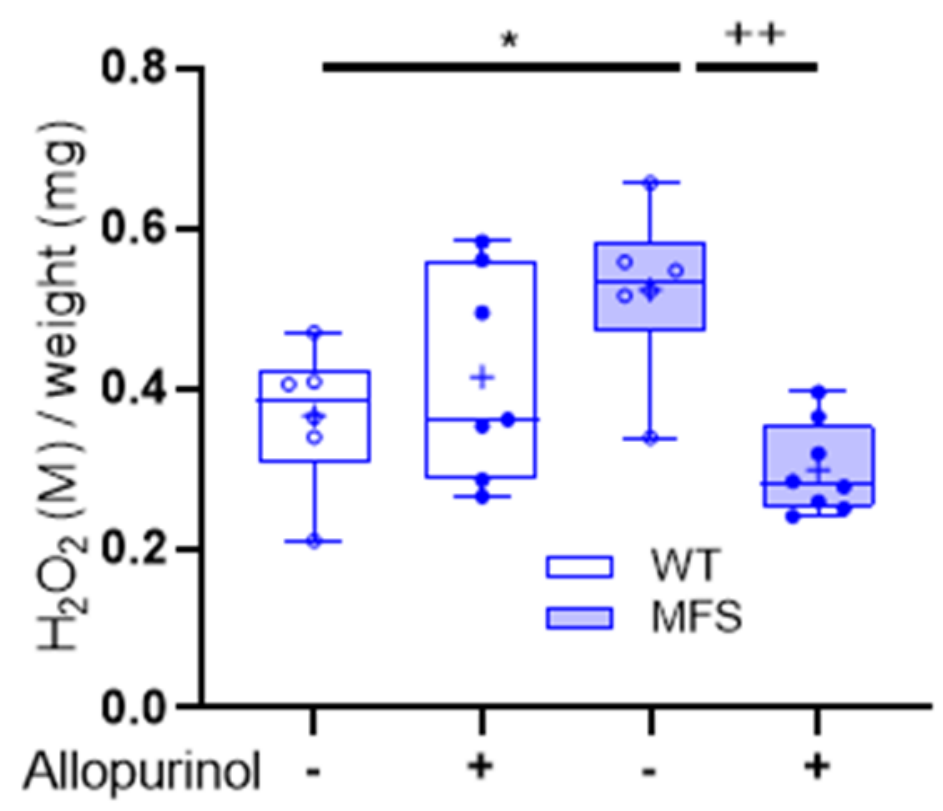

Figure 5. In vitro treatment of allopurinol reduces the formation of $\mathrm{H}_{2} \mathrm{O}_{2}$ in the ascending aorta of young MFS mice. Aortic rings of the part most proximal to the heart of the ascending aorta of WT and MFS mice of 3 months of age were in vitro treated or not with allopurinol $(100 \mu \mathrm{M}$, final concentration). Results shown here are those obtained after $2 \mathrm{~h}$ of allopurinol treatment. Statistical test: Kruskal-Wallis test with Dunn's multiple comparison. ${ }^{*} P \leq 0.05$ and ${ }^{++} P \leq 0.01$; ${ }^{*}$ significance between WT and MFS (genotype); ${ }^{+}$significance between experimental groups. Number of samples analyzed: 6-8. 
A

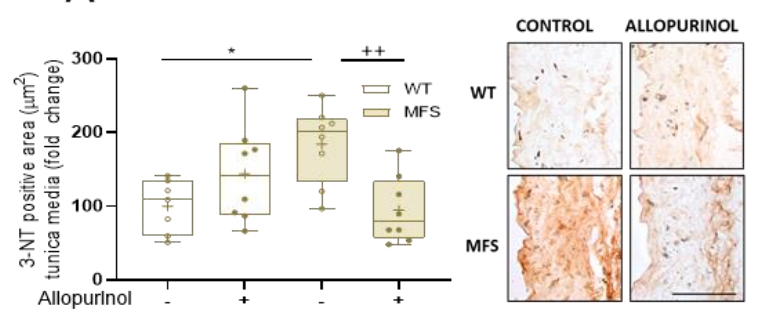

B

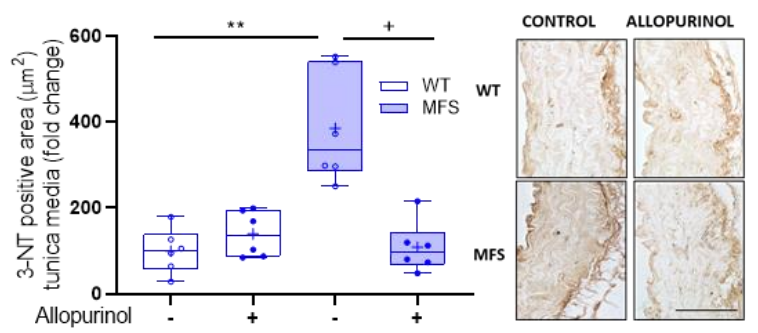

C
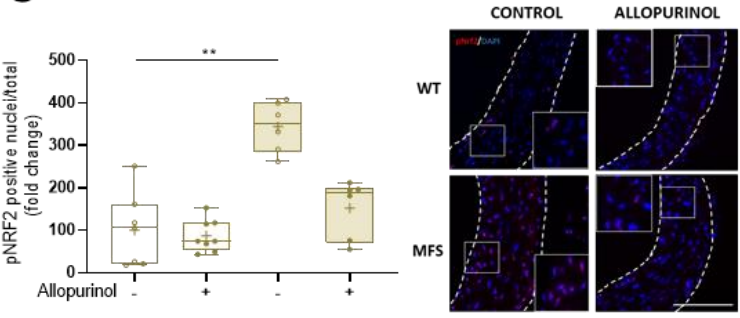

D

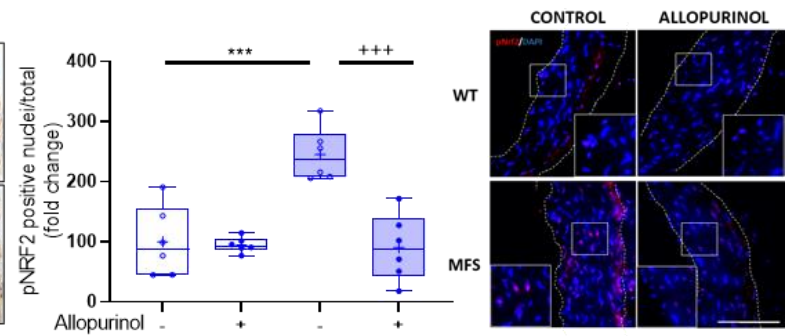

Figure 6. Allopurinol inhibits oxidative stress reactions occurring in the Marfan aortic media. (A and B) Quantitative analysis and representative images of the 3NT levels in the aortic media evidenced by HRP immunohistochemistry after palliative (PA1; A) and preventive (PE; B) treatments with allopurinol in WT and MFS mice. Bar, $100 \mu \mathrm{m}$. (C and D) Quantitative analysis and representative images of the nuclear translocation of the phosphorylated form of NRF2 in VSMC of the tunica media of WT and MFS mice treated with allopurinol palliatively (PA1; C) and preventively (PE; D). Insets in the immunofluorescent images detail the nuclear localization of pNRF2. Bar, $100 \mu \mathrm{m}$. Statistical test: (A-D) Kruskal-Wallis and Dunn's multiple comparison tests. ${ }^{* * *},{ }^{+++} P \leq 0.001{ }^{* *},{ }^{++} P \leq 0.01$ and ${ }^{*},+P \leq 0.05$; ${ }^{*}$ significance between genotype; +significance between treatments. Number of aortae analyzed: 6-8 (A1 and A2) and 6 (B1 and B2). 


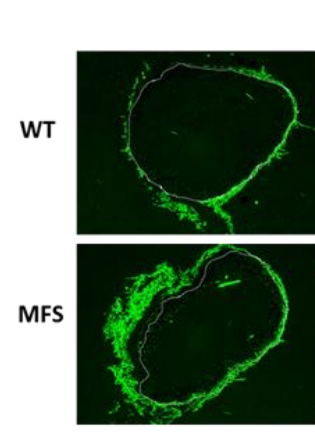

+ ALO
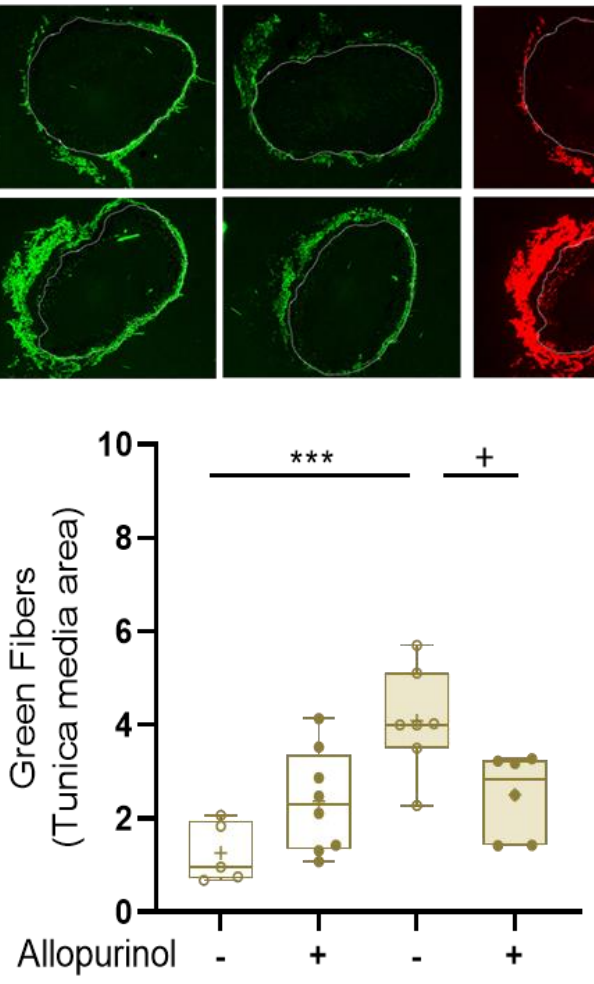

+ ALO
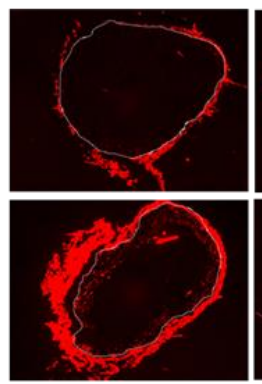
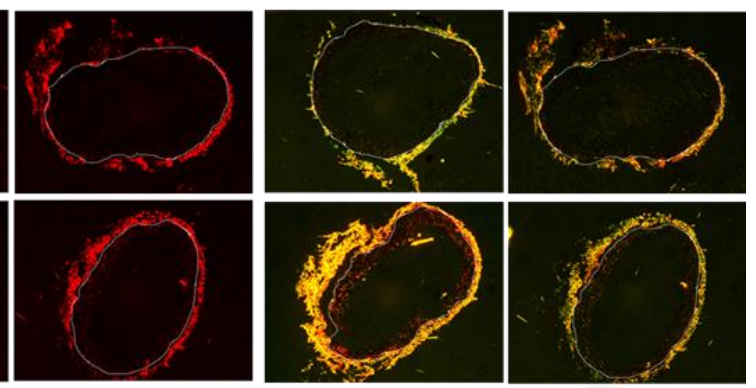

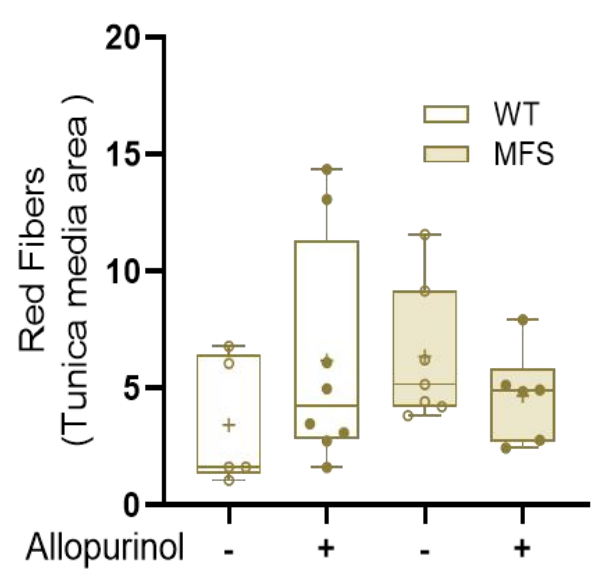

Figure 7. Palliative treatment with allopurinol reverts the MFS-associated fibrotic remodeling of the tunica media. Immature (green) and mature (red) collagen fibers of the tunicae media and adventitia of WT and MFS aortae stained with Picrosirius red visualized under the polarized microscope. WT and MFS mice treated or not with allopurinol in a palliative (PA1) manner. Representative fluorescent images of the whole aorta where white dashed lines display the limit between the tunicae media (inner) and adventitia (outer). The respective quantitative analysis of both types of collagen fibers is also shown. Statistical test Kruskal-Wallis and Dunn's multiple comparison tests. ${ }^{* * *} \mathrm{P} \leq 0.001$ and ${ }^{+} \mathrm{P} \leq 0.05$; ${ }^{*}$ significance between genotype; +significance between treatments. Number of aortae analyzed: 5-8. 
A

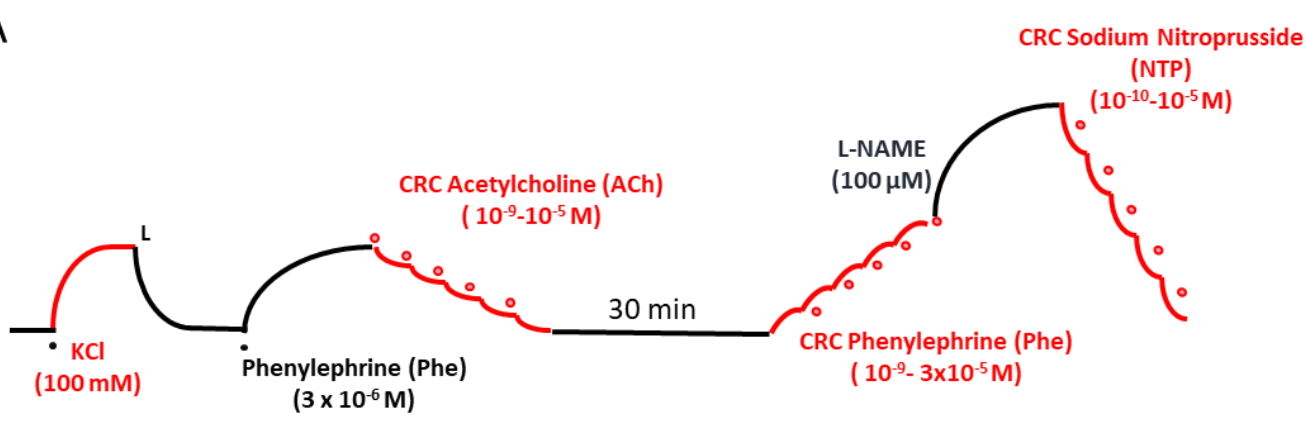

B

C
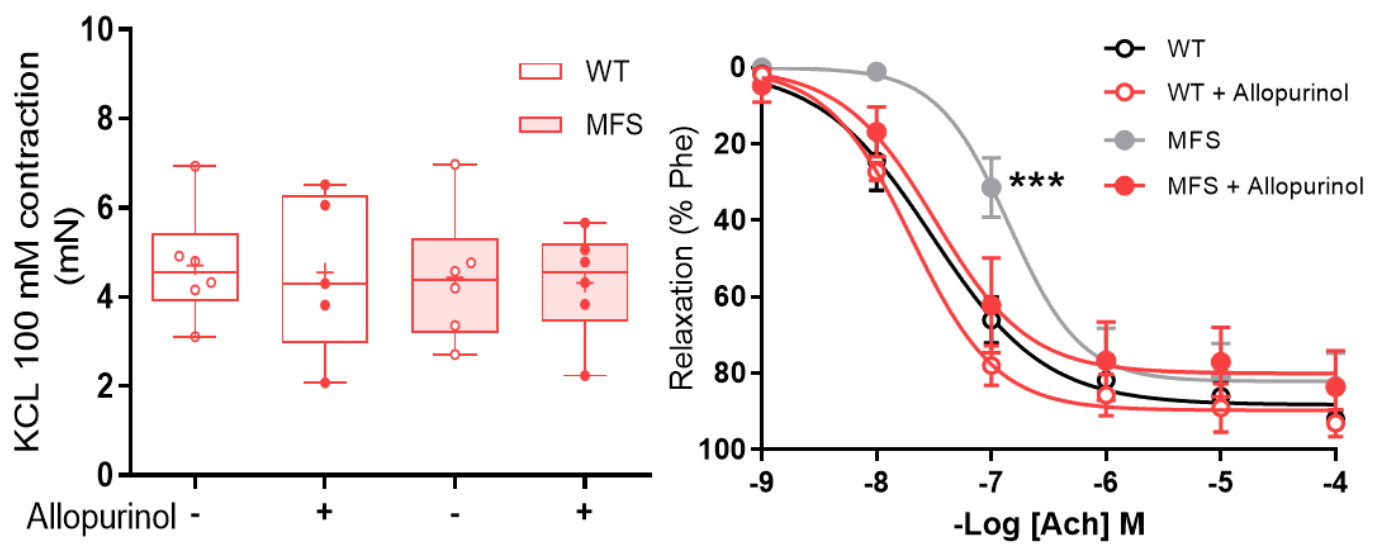

D

$\mathrm{E}$
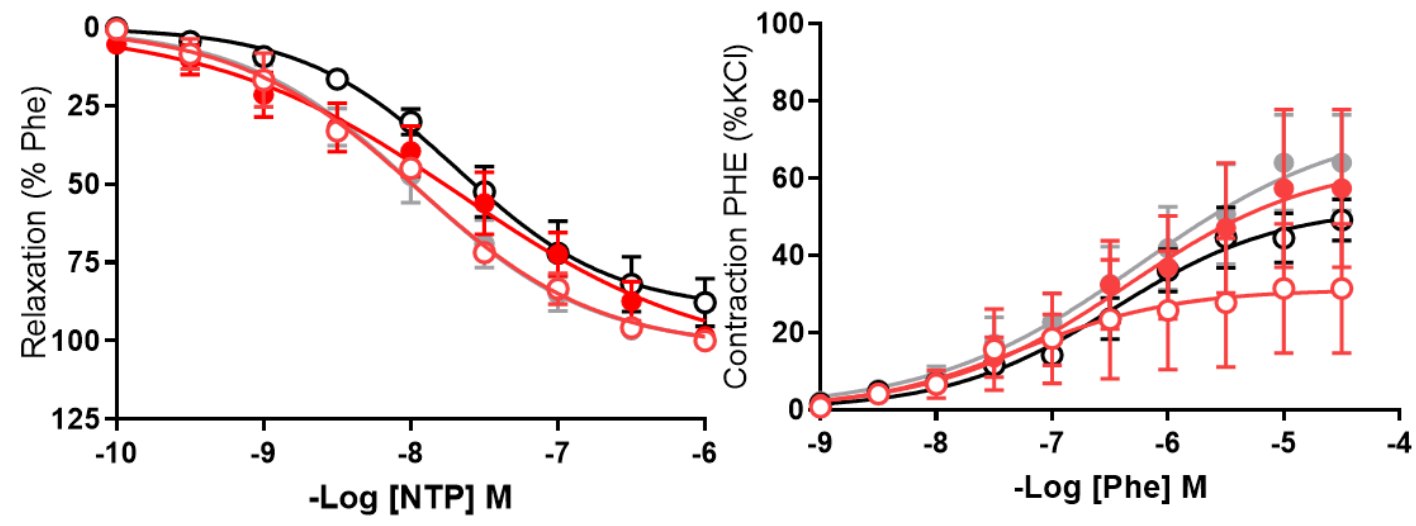

Figure 8. Allopurinol prevents the endothelial vasodilation dysfunction of MFS aorta. (A) Experimental protocol for the wire-myography experiments carried out in isolated 9-month-old ascending aorta of the diverse experimental groups indicated in the following panels. (B) Physiological state test of aortic reactivity following the addition of $\mathrm{KCl}(100 \mathrm{mM})$. (C) Relaxation of aortic reactivity following ACh addition. (D) Relaxation reactivity after the addition of the NO donor sodium nitroprusside. (E) Contraction aortic reactivity after the addition of phenylephrine. Statistical tests: (B) Two-way ANOVA and Tukey post-test; (C-E): non-liner regression by fitting Phe/ACh/NTP concentration-response curves to a sigmoidal dose response. ${ }^{* * *} P \leq 0.001$. Number of aortae analyzed per experimental group: 4-6. 
bioRxiv preprint doi: https://doi.org/10.1101/2021.10.13.464182; this version posted October 14, 2021. The copyright holder for this preprint (which was not certified by peer review) is the author/funder. All rights reserved. No reuse allowed without permission.

SUPPLEMENTARY MATERIAL:

MATERIAL AND METHODS, SUPPLEMENTAL FIGURES (S1-S8)

AND TABLES (S1-S6)

\section{ALLOPURINOL BLOCKS THE FORMATION AND PROGRESSION OF AORTIC ANEURYSM IN A MOUSE MODEL OF MARFAN SYNDROME ACTING AS A SCAVENGER OF REACTIVE OXYGEN SPECIES}

Sentence summary: Allopurinol avoids the formation and progression of aortopathy in Marfan syndrome mice

Isaac Rodríguez-Rovira ${ }^{1,}$, , Cristina Arce ${ }^{1,{ }^{*}}$, Karo de Rycke ${ }^{1,{ }^{*}, \mathbb{N},}$, Belén Pérez ${ }^{2}$, Aitor Carretero ${ }^{3}$, Marc Arbonés ${ }^{1}$, Gisela Teixidò-Turà ${ }^{4}$, Mari Carmen Gómez-Cabrera ${ }^{3}$, Victoria Campuzano ${ }^{1,5}$, Francesc Jiménez-Altayó ${ }^{2}$ and Gustavo Egea ${ }^{1, \#}$

1 Departament of Biomedical Sciences, University of Barcelona School of Medicine and Health Sciences and IDIBAPS, 08036 Barcelona (Spain).

2 Department of Pharmacology, Toxicology and Therapeutics, Neuroscience Instiute, School of Medicine, Autonomous University de Barcelona, 08193 Cerdanyola del Vallès, Spain.

3 Department of Physiology, Faculty of Medicine, University of Valencia, CIBERFES, Fundación Investigación Hospital Clínico Universitario/INCLIVA, Valencia, Spain.

${ }^{4}$ Department of Cardiology, Hospital Universitari Vall d'Hebron, Barcelona, Spain. CIBER-CV, Vall d'Hebron Institut de Recerca (VHIR), Barcelona, Spain 5 Centro de Investigación Biomédica en Red de Enfermedades Raras (CIBERER), ISCIII, Spain.

\# Corresponding author. Email: gegea@ub.edu (GE)

* These authors contributed equally to this work.

II Present address: Center for Medical Genetics, Department of Biomolecular Medicine, Ghent University, Ghent, 9000, Belgium.

\section{MATERIAL AND METHODS}

\section{Human tissue collection, mice, and experimental designs}

Healthy ascending aortic tissue was collected from heart donors via the organ donation organization at the Hospital Clínic i Provincial (Barcelona, Spain) and Hospital de Bellvitge, (L'Hospitalet de Llobregat, Barcelona, Spain). The age and gender of heart donors were unknown because Spanish law protects personal information about organ donors. Ascending aortic aneurysm samples were collected from MFS patients (with ages ranging from 23 to 59 years) undergoing aortic aneurysm repair surgery. All the patients in whom aortae were resected fulfilled Marfan diagnostic criteria according to Ghent nosology, but no genetic information regarding putative FBN1 mutations was available. For each patient, we obtained a $3 \mathrm{x}$ 
bioRxiv preprint doi: https://doi.org/10.1101/2021.10.13.464182; this version posted October 14, 2021. The copyright holder for this preprint (which was not certified by peer review) is the author/funder. All rights reserved. No reuse allowed without permission. $3 \mathrm{~cm}$ sample from two areas: the dilated zone, corresponding to the sinuses of Valsalva, and the apparently adjacent virtually non-dilated aorta, corresponding to the distal ascending aorta. The aortae were maintained in cold saline solution or cardioprotective solution before delivery to the laboratory. Human tissues were collected with the required approval from the Institutional Clinical Review Board of Spanish clinical centers, and the patients' written consent conformed to the ethical guidelines of the 1975 Declaration of Helsinki. All aortic tissues described in the manuscript are those obtained from Spanish Marfan patients and heart donors. Due to the Spanish Data Protection Act, we do not have access to their clinical history or personal data.

Marfan syndrome mice with fibrillin-1 mutation (Fbn1 $\left.{ }^{\mathrm{Cl041G/+}}\right)$ (hereafter, MFS mice) were purchased from The Jackson Laboratory (Bar Harbor, ME 04609, USA). MFS and sex- and age-matched wild-type littermates (WT mice) were maintained on a C57BL/6J genetic background. All mice were housed according to the University of Barcelona institutional guidelines (constant room temperature at $22^{\circ} \mathrm{C}$, controlled environment 12/12-hour light/dark cycle, $60 \%$ humidity and ad libitum access to food and water). Animal care and colony maintenance conformed to the European Union (Directive 2010/63/EU) and Spanish guidelines (RD 53/2013) for the use of experimental animals. Ethical approval was obtained from the local animal ethics committee (CEEA protocol approval number 10340).

WT and MFS mice were administered allopurinol (hereafter ALO) (A8003, Sigma-Aldrich;) diluted in drinking water (20 mg/kg/day). The dose was calculated based on the human equivalent dose formula to convert the appropriate dose between species (1). ALO was fully replaced each third day of treatment. We performed two experimental ALO treatment approaches: preventive (PE) and palliative (PA). For PE treatment, ALO was administered to the pregnant WT mother, maintained after giving birth (lactation period of 25 days) and thereafter maintained in drinking water to weaned babies until 3 months of age. For PA treatments, ALO was administered to mice of 2 months of age until 6 or 9 months-old being a respective effective treatment of 16 and 28 weeks (named PA1 and PA2, respectively) (Supplementary Figure 2). At each outcome time points, mice were subjected to echocardiographic analysis, the liver and ascending aorta were dissected and fixed for paraffin embedding for (immuno)histological studies or immersed in RNA Later (R-0901, Sigma Aldrich), frozen in liquid nitrogen and stored at $-80^{\circ} \mathrm{C}$ for molecular tests.

\section{Echocardiography}

Two-dimensional transthoracic echocardiography was performed in all animals under $1.5 \%$ inhaled isoflurane. Each animal was scanned 12-24 hours before sacrifice. Images were obtained with a $10-13 \mathrm{MHz}$ phased array 
bioRxiv preprint doi: https://doi.org/10.1101/2021.10.13.464182; this version posted October 14, 2021. The copyright holder for this preprint (which was not certified by peer review) is the author/funder. All rights reserved. No reuse allowed without permission. linear transducer (IL12i GE Healthcare, Madrid, Spain) in a Vivid Q system (GE Healthcare, Madrid, Spain). Images were recorded and later analyzed offline using commercially available software (EchoPac v.08.1.6, GE Healthcare, Madrid, Spain). Proximal aortic segments were assessed in a parasternal long-axis view. The aortic root diameter was measured from inner edge to inner edge in end-diastole at the level of the sinus of Valsalva. All echocardiographic measurements were carried out in a blinded manner by two independent investigators at two different periods, and with no knowledge of genotype and treatment.

\section{Histology and histomorphometry}

Paraffin-embedded tissue arrays of mice aortae from different experimental sets were cut into $5 \mu \mathrm{m}$ sections. Elastic fiber ruptures were quantified by counting the number of large fiber breaks in tissue sections stained with Verhoeff-Van Gieson. Breaks larger than $20 \mu \mathrm{m}$ were defined as evident large discontinuities in the normal circumferential continuity $\left(360^{\circ}\right)$ of each elastic lamina in the aortic media (2). They were counted along the length of each elastic lamina in four different, representative images of three non-consecutive sections of the same ascending aorta. All measurements were carried out in a blinded manner by two different observers with no knowledge of genotype and treatment. Images were captured using a Leica Leitz DMRB microscope (40x oil immersion objective) equipped with a Leica DC500 camera and analyzed with Fiji Image $\mathbf{J}$ Analysis software.

\section{Immunohistochemistry and immunofluorescence staining}

For immunohistochemistry and/or immunofluorescence, paraffinembedded aortic tissue sections ( $5 \mu \mathrm{m}$ thick) were deparaffinized and rehydrated prior to unmasking the epitope. Horse radish peroxidase (HRP)based immunohistochemistry was used to stain aortic tissue sections for xanthine oxidoreductase (XOR) and 3-nitrotyrosine (3-NT). To unmask XOR epitopes, aortic tissue sections were treated with a retrieval solution $(10 \mathrm{mM}$ sodium citrate, $0.05 \%$ Tween, $\mathrm{pH}$ 6) for 30 minutes in the steamer at $95^{\circ} \mathrm{C}$. No antigen retrieval was used for 3-NT. Next, sections were incubated for $10 \mathrm{~min}$ with peroxidase blocking solution (Dako Real Peroxidase-blocking solution; S202386-2), rinsed three times with PBS and then incubated with $1 \%$ BSA in PBS prior to overnight incubation at $4^{\circ} \mathrm{C}$ with the respective primary polyclonal antibodies anti-XOR (1:50; Rockland 200-4183S) or anti-3-NT (1:200; Merck Millipore 06-284). On the next day, sections were incubated with the manufacturer's goat anti-rabbit secondary antibody solution (1:500; Abcam ab97051) for 1 hour followed by the Liquid DAB+Substrate Chromogen System (Dako System HRP) for 1 minute at room temperature. 
bioRxiv preprint doi: https://doi.org/10.1101/2021.10.13.464182; this version posted October 14, 2021. The copyright holder for this preprint (which was not certified by peer review) is the author/funder. All rights reserved. No reuse allowed without permission. HRP-stained non-consecutive sections were visualized under a Leica Leitz DMRB microscope (40x immersion oil objective).

Immunofluorescence was used to stain pNrf2 in aortic sections. Sections were treated first with heat-mediated retrieval solution (1 M TrisEDTA, $0.05 \%$ Tween, $\mathrm{pH} 9$ ) for $30 \mathrm{~min}$ in the steamer at $95^{\circ} \mathrm{C}$. Next, sections were incubated for 20 minutes with ammonium chloride $\left(\mathrm{NH}_{4} \mathrm{Cl}, 50 \mathrm{mM}\right.$, $\mathrm{pH}$ 7.4) to block free aldehyde groups, followed by a permeabilization step using $0.3 \%$ Triton $\mathrm{X}-100$ for 10 minutes and then treated with $1 \%$ BSA blocking buffer solution for 2 hours prior to overnight incubation with monoclonal anti-pNRF2 (1:50; Abcam ab76026) in a humidified chamber at $4{ }^{\circ} \mathrm{C}$. On the next day, sections were rinsed with PBS, followed by $60 \mathrm{~min}$ incubation with the secondary antibody goat anti-rabbit Alexa $647(1: 1,000$, A-21246, Invitrogen). Sections were counterstained with DAPI $(1: 10,000)$ and images were acquired using an AF6000 widefield fluorescent microscope (Leica). For quantitative analysis of immunostainings, four areas of each ascending aorta section were quantified with Image J software. All measurements were carried out in a blinded manner by two independent investigators.

\section{Uric acid, allantoin and hydrogen peroxide measurements in blood plasma and/or ascending aortic rings}

Whole blood from mice was collected directly from the left ventricle just before the aortic tissue was dissected. Thereafter, the blood plasma was obtained by centrifugation of unclotted blood at $3,000 \mathrm{rpm}$ for $10 \mathrm{~min}$ at $4^{\circ} \mathrm{C}$ and immediately stored frozen at $-80^{\circ} \mathrm{C}$.

Measurement of uric acid (UA) in blood plasma was evaluated by high-performance liquid chromatography (HPLC) with ultraviolet detection. The method used for UA extraction from biological samples was an adaptation of a method previously described (3). The plasma (100 $\mu \mathrm{l})$ was deproteinized with $10 \%$ trichloroacetic acid. Ten $\mu$ l of supernatant was injected into the HPLC system made up of a Perkin Elmer series 200 Pump, a 717 plus Auto sampler, a 2487 Dual $\lambda$ absorbance detector, and a reversephase ODS2 column (Waters, Barcelona, Spain; $4.6 \mathrm{~mm} \cdot 200 \mathrm{~mm}, 5 \mu \mathrm{m}$ particle size). The mobile phase was methanol/ammonium acetate 5 $\mathrm{mM} /$ acetonitrile $(1: 96: 3 \mathrm{v} / \mathrm{v})$, which was run with an isocratic regular low flow rate of $1.2 \mathrm{~mL} / \mathrm{min}$ and the wavelength UV detector was set at $292 \mathrm{~nm}$. UA eluted at a retention time of 2.9 minutes. Quantification was performed by external calibration. The UA detection limit in plasma was $10 \mathrm{ng} / \mathrm{mL}$

For the determination of allantoin in plasma, an adapted protocol was used as previously described (4). Briefly, plasma $(60 \mu \mathrm{l})$ was deproteinized with acetonitrile $(25 \mu \mathrm{l})$. Samples were centrifuged $(5 \mathrm{~min}, 12,000 \mathrm{~g})$. Ten $\mu 1$ of supernatant was injected into the HPLC system. Separation of allantoin was performed on a Synergy Hydro-RP C-18 reversed-phase column $(250 \times$ 
bioRxiv preprint doi: https://doi.org/10.1101/2021.10.13.464182; this version posted October 14, 2021. The copyright holder for this preprint (which was not certified by peer review) is the author/funder. All rights reserved. No reuse allowed without permission. 4.6 mm I.D., $5 \mathrm{~m}$ particle size) from Phenomenex (Torrance, CA, USA). Allantoin elution (at $4 \mathrm{~min}$ ) was performed with potassium dihydrogen phosphate (10 mM, pH 2.7):acetonitrile (85:15) and ultraviolet detection (at $235 \mathrm{~nm})$.

Hydrogen peroxide $\left(\mathrm{H}_{2} \mathrm{O}_{2}\right)$ in plasma $(50 \mu \mathrm{L})$ and dissected aortic tissue was determined utilizing a commercial assay kit (ab102500 Abcam, Cambridge, UK). In the case of aortic tissue, freshly dissected ascending aortic rings from 3 and 6 month-old mice were divided in two equal portions along the proximal-distal heart axis, both portions were then immersed in DMEM and incubated with OxiRed probe and HRP following the manufacturer's instructions. After a basal measurement, one of the two aortic portions was treated with allopurinol $(100 \mu \mathrm{M}$, final concentration) while the other was treated with the vehicle (physiological serum). Measurements were performed after 120 minutes. Results were normalized by weight of the respective aortic rings. Fluorescence was measured with a Synergy fluorimeter $(\mathrm{Ex} / \mathrm{Em}=535 / 587 \mathrm{~nm})$.

\section{Myography tissue preparation and vascular reactivity}

Segments of the ascending aorta from 9-month-old mice treated or not with ALO were dissected free of fat and placed in a cold physiological salt solution (PSS; composition in mM: $\mathrm{NaCl} 112.0 ; \mathrm{KCl} 4.7 ; \mathrm{CaCl}_{2} 2.5 ; \mathrm{KH}_{2} \mathrm{PO}_{4}$ 1.1; $\mathrm{MgSO}_{4} 1.2 ; \mathrm{NaHCO}_{3} 25.0$ and glucose 11.1) gassed with $95 \% \mathrm{O}_{2}$ and $5 \% \mathrm{CO}_{2}$. Ascending aortic segments $(2-3 \mathrm{~mm})$ were set up on an isometric wire myograph (model 410A; Danish Myo Technology, Aarhus, Denmark) filled with PSS $\left(37^{\circ} \mathrm{C} ; 95 \% \mathrm{O}_{2}\right.$ and $\left.5 \% \mathrm{CO}_{2}\right)$ as previously described (5). The vessels were stretched to $6 \mathrm{mN}$ as reported (6), rinsed and allowed to equilibrate for $45 \mathrm{~min}$. Tissues were then contracted twice with $100 \mathrm{mM} \mathrm{KCl}$ every $5 \mathrm{~min}$. After rinsing, vessels were left to equilibrate for an additional 30 min before starting the experiments. Vasodilatation caused by nitric oxide (NO) produced either by the endothelium itself (triggered by acetylcholine/ACh) or by the NO donor sodium nitroprusside (NTP) were determined by cumulative concentration-response curves (CRCs) of respective relaxation to ACh $\left(10^{-9}-10^{-5} \mathrm{M}\right)$ or NTP $\left(10^{-10}-10^{-5} \mathrm{M}\right)$ after phenylephrine (Phe; $3 \times 10^{-6} \mathrm{M}$ ) induced precontracted vessel. To study the impact of ALO on contractile responses triggered by $\alpha_{1}$-adrenergic stimulation, the cumulative concentration-response curves (CRCs) of Phe $\left(10^{-9}\right.$ to $\left.3 \times 10^{-5} \mathrm{M}\right)$ induced contraction were evaluated. Relaxations to ACh are expressed as a percentage of Phe-precontracted level. Contractions to Phe are expressed as a percentage of the tone generated by $100 \mathrm{mM} \mathrm{KCl}$. Data from CRCs were plotted using the Graph Pad Software version 8.0 (San Diego, CA, USA) with sigmoid curve fitting (variable slope) performed by non-linear regression. These curves were used to derive the values for $\mathrm{E}_{\max }$ 
bioRxiv preprint doi: https://doi.org/10.1101/2021.10.13.464182; this version posted October 14, 2021. The copyright holder for this preprint (which was not certified by peer review) is the author/funder. All rights reserved. No reuse allowed without permission. (the maximal relaxant response) and $\mathrm{pEC}_{50}(-\log$ of the agonist concentration needed to produce $50 \%$ of $\mathrm{E}_{\max }$ ).

\section{Quantitative Real-Time PCR}

Total RNA from ascending aortae was extracted using Trizol $^{\odot}$ following manufacturer's recommendations (Invitrogen, USA). RNA concentration was quantified using Nanodrop (Agilent, USA). mRNA expression levels were determined by quantitative real-time PCR (qRTPCR) using the SYBR green detection kit. mRNA levels encoding for XOR were expressed relative to GAPDH, which was used as housekeeping. qPCR reactions were performed following the protocol guidelines of the SYBR green master mix (ThermoFisher Scientific, Waltham, MA, USA). Briefly, reactions were performed in a total volume of $10 \mu \mathrm{L}$, including $5 \mu \mathrm{L}$ of SYBR green PCR master mix, $2 \mu \mathrm{M}$ of each primer, $2 \mu \mathrm{L}$ of nuclease-free water, and $2 \mu \mathrm{L}$ of the previously reverse-transcribed cDNA ( $25 \mathrm{ng}$ ) template on a 368-well iCycler iQ PCR plater (Bio-Rad). All reactions were carried out in duplicate for each sample. The thermocycling profile included 45 cycles consisting of denaturation at $95^{\circ} \mathrm{C}$ for 15 seconds and annealing and elongation at $60^{\circ} \mathrm{C}$ for 60 seconds. Cycle threshold $(\mathrm{Ct})$ values for each gene were referenced to the internal control (comparative $\mathrm{Ct}(\Delta \Delta \mathrm{Ct})$ ) and converted to the linear form relative to corresponding levels in WT aortae. The primer sequences for the murine genes used in this study are shown in Supplementary Table 1.

\section{Xanthine dehydrogenase and xanthine oxidase enzymatic activities}

XO activity was determined in WT and MFS mice from liver and aorta lysates using a fluorimetry-based method (7). Part of the liver and total aorta were homogenized with 5 volumes per gram of tissue of $0.25 \mathrm{M}$ sucrose, 10 mM DTT, 0.2 mM PMSF, 0.1 mM EDTA and $50 \mathrm{mM} \mathrm{K-phosphate,} \mathrm{pH}$ 7.4. Homogenates were centrifuged for 30 minutes at $15,000 \mathrm{~g}$ and the supernatants were obtained for XO activity. XO activity was measured by calculating the slope of the increase in fluorescence after adding pterin $(0.010 \mathrm{mmol} / \mathrm{L})$, which measures the conversion of pterin to isoxanthopterin. $\mathrm{XO}+\mathrm{XDH}$ activity was likewise determined with methylene blue $(0.010$ $\mathrm{mmol} / \mathrm{L}$ ), which replaces NAD+ as an electron acceptor. The reaction was stopped by adding allopurinol $(50 \mu \mathrm{mol} / \mathrm{L})$. To calibrate the fluorescence signal, the activity of a standard concentration of isoxanthopterin was measured. Values are expressed as $\mathrm{nmol} / \mathrm{min}$ per $\mathrm{g}$ of protein. The protein concentration of homogenates was determined with the Bradford assay.

\section{Western blotting}

Total aortae from mice and dilated and non-dilated aortic zones of human patients and healthy controls were dissected and homogenized with 
bioRxiv preprint doi: https://doi.org/10.1101/2021.10.13.464182; this version posted October 14, 2021. The copyright holder for this preprint (which was not certified by peer review) is the author/funder. All rights reserved. No reuse allowed without permission. bullet blender and beads in RIPA buffer containing 1\% Triton X-100, $50 \mathrm{mM}$ Tris- $\mathrm{HCl}, \mathrm{pH} 7.5,10 \mathrm{mM}$ EGTA, $150 \mathrm{mM} \mathrm{NaCl}$, protease inhibitors $(2 \mathrm{mM}$ phenylmethylsulphonyl fluoride, $10 \mathrm{~g} / \mathrm{L}$ aprotinin, and $1 \mathrm{~g} / \mathrm{L}$ leupeptin, $1 \mathrm{~g} / \mathrm{L}$ pepstatin), and phosphatase inhibitors (2 $\mathrm{mM} \mathrm{Na}_{3} \mathrm{VO}_{4}$ and $100 \mathrm{mM} \mathrm{NaF}$ ). Samples were centrifuged at $1000 \mathrm{~g}$ for $15 \mathrm{~min}$ at $4{ }^{\circ} \mathrm{C}$, the supernatants were collected, and the protein concentration was determined using the Dc protein assay kit (Bio-Rad). Proteins were denatured in $62.5 \mathrm{mM}$ Tris- $\mathrm{HCl}, \mathrm{pH} 6.8$, $2 \%$ (w/v) SDS, $10 \%$ glycerol, $140 \mathrm{mM}$ mercaptoethanol, and $0.1 \%$ (w/v) bromophenol blue, heated at $100^{\circ} \mathrm{C}$ for $5 \mathrm{~min}$, and resolved in denaturing $7 \%$ polyacrylamide gels. Proteins were transferred to nitrocellulose membranes and washed three times in Tris-buffered saline containing $0.1 \%$ Tween 20 (TBS-T). After blocking [TBS-T solution plus $5 \%$ bovine serum albumin (A9647, Sigma) and 5\% skimmed milk] at room temperature for $1 \mathrm{~h}$, the membranes were blotted overnight at $4{ }^{\circ} \mathrm{C}$ with the following primary antibody: anti-XOR (1:500 Abcam ab109235 for human samples; 1:500 SantaCruz sc-398548 for mouse samples). After primary antibody incubation overnight, the membranes were washed with TBS-T and incubated for $1 \mathrm{~h}$ at room temperature with the appropriate HRP conjugated secondary antibody (1:3,000 anti-rabbit W401B antibody from Promega), and the reaction was finally visualized with the Western Blotting Luminol Reagent (Santa Cruz Biotechnology). Western blot replicates were quantified using a computer-assisted densitometric analysis (Gel-Pro Analyzer, version 4; Media Cybernetics).

\section{Blood pressure measurements}

Systolic blood pressure measurements were acquired in 9 month-old animals by the tail-cuff method and using the Niprem 645 non-invasive blood pressure system (Cibertec, Madrid, Spain). Mice were positioned on a heating pad and all measurements were carried out in the dark to minimize stress. All animals were habituated to the tail-cuff by daily training 1 week prior to the final measurements. Then, the systolic blood pressure was recorded over the course of 3 days. For quantitative analysis, the mean value of 3 measurements per day were used for each animal. All measurements were carried out in a blinded manner with no knowledge of genotype and experimental group.

\section{Collagen content measurements}

Collagen content was evaluated with PicroSirius Red Staining method. Briefly, paraffin-embedded tissue arrays of mice aortae from different experimental sets were cut into $5 \mu \mathrm{m}$ sections. Deparaffination was performed with xylene, and standard progressive rehydration from ethanol to distilled water $\left(\mathrm{dH}_{2} \mathrm{O}\right)$. After rehydration, samples were immersed in phophomolybdic acid $0,2 \%$ for 2 minutes and rinsed with $\mathrm{dH}_{2} \mathrm{O}$. Then, 
bioRxiv preprint doi: https://doi.org/10.1101/2021.10.13.464182; this version posted October 14, 2021. The copyright holder for this preprint (which was not certified by peer review) is the author/funder. All rights reserved. No reuse allowed without permission. samples were immersed in picrosirius red (previously prepared with picric acid (Fluka 74069) and direct red 80 (Aldrich 365548) for 110 minutes. Afterwards, samples were rinsed with $\mathrm{dH}_{2} \mathrm{O}$ for 5 minutes and immersed in $\mathrm{HCl} 0,01 \mathrm{~N}$ for 2 minutes. To avoid background, unstaining was performed with ethanol $75 \%$ for 45 seconds. Finally, slides were dehydrated with absolute ethanol for 5 minutes and fixated with xylene 2 times for 10 minutes each and coverslips mounted with DPX. Images were captured using a Leica Leitz DMRB microscope (10x and 40x oil immersion objective) equipped with a Leica DC500 camera and analyzed with Fiji Image J Analysis software with a predesigned macro program (8).

\section{Statistics}

Data are presented either as bars showing the mean \pm standard error of the mean (SEM) or boxplots, in which the error bars represent minimum and maximum values, the horizontal bars and the crosses indicate median and mean values, respectively, and the extremities of the boxes indicate interquartile ranges. Normal distribution and equality of error variance data was respectively verified with Kolmogorov-Smirnov/Shapiro Wilk tests and Levene's test with the IBM SPSS Statistics Base 22.0 before parametric tests were used. Differences between three or four groups were evaluated using one-way or two-way ANOVA with Tukey's post-hoc test if data was normally distributed, and variances were equal or Kruskal-Wallis test with Dunn's post-hoc test was conducted if data was not normally distributed. For comparison of two groups, the unpaired t-test was utilized when the data was normally distributed, and variances were equal or the Mann-Whitney U test if data did not follow a normal distribution. A value of $P \leq 0.05$ was considered statistically significant. Data analysis was carried out using GraphPad Prism, Version 8 (GraphPad Software, La Jolla, CA).

\section{REFERENCES}

1. S. Reagan-Shaw, M. Nihal, N. Ahmad, Dose translation from animal to human studies revisited. FASEB J. 22, 659-61 (2008).

2. C. Arce, I. Rodríguez-Rovira, K. de Rycke, K. Durán, V. Campuzano, I. Fabregat, F. Jiménez-Altayó, P. Berraondo, G. Egea, Anti-TGF $\beta$ (Transforming Growth Factor $\beta$ ) Therapy With Betaglycan-Derived P144 Peptide Gene Delivery Prevents the Formation of Aortic Aneurysm in a Mouse Model of Marfan Syndrome. Arterioscler. Thromb. Vasc. Biol. 41, e440-e452 (2021).

3. K. M. Kim, G. N. Henderson, X. Ouyang, R. F. Frye, Y. Y. Sautin, D. I. Feig, R. J. Johnson, A sensitive and specific liquid chromatography-tandem mass spectrometry method for the determination of intracellular and extracellular uric acid. J. Chromatogr. B. Analyt. Technol. Biomed. Life. Sci. 877, 2032-8 (2009).

4. M. A. S. el Mubarak, F. N. Lamari, C. Kontoyannis, Simultaneous determination of allantoin and glycolic acid in snail mucus and cosmetic 
bioRxiv preprint doi: https://doi.org/10.1101/2021.10.13.464182; this version posted October 14, 2021. The copyright holder for this preprint (which was not certified by peer review) is the author/funder. All rights reserved. No reuse allowed without permission. creams with high performance liquid chromatography and ultraviolet detection, J. Chromatogr. 1322, 49-53 (2013).

5. Y. Onetti, F. Jiménez-Altayó, M. Heras, E. Vila, A. P. Dantas, Western-type diet induces senescence, modifies vascular function in non-senescence mice and triggers adaptive mechanisms in senescent ones. Exp. Gerontol. 48,14109 (2013).

6. A. W. Y. Chung, K. Au Yeung, S. F. Cortes, G. G. S. Sandor, D. P. Judge, H. C. Dietz, C. van Breemen, Endothelial dysfunction and compromised eNOS/Akt signaling in the thoracic aorta during the progression of Marfan syndrome. Br. J.I Pharmacol. 150, 1075-83 (2007).

7. J. S. Beckman, D. A. Parks, J. D. Pearson, P. A. Marshall, B. A. Freeman, A sensitive fluorometric assay for measuring xanthine dehydrogenase and oxidase in tissues. Free Radic. Biol. Med. 6, 607-15 (1989).

8. C. Rubies, A.-P. Dantas, M. Batlle, M. Torres, R. Farre, G. Sangüesa, J. M. Montserrat, L. Mont, I. Almendros, E. Guasch, Aortic remodelling induced by obstructive apneas is normalized with mesenchymal stem cells infusion. Sci. Rep. 9, 11443 (2019).

\section{SUPPLEMENTARY FIGURES AND LEGENDS}

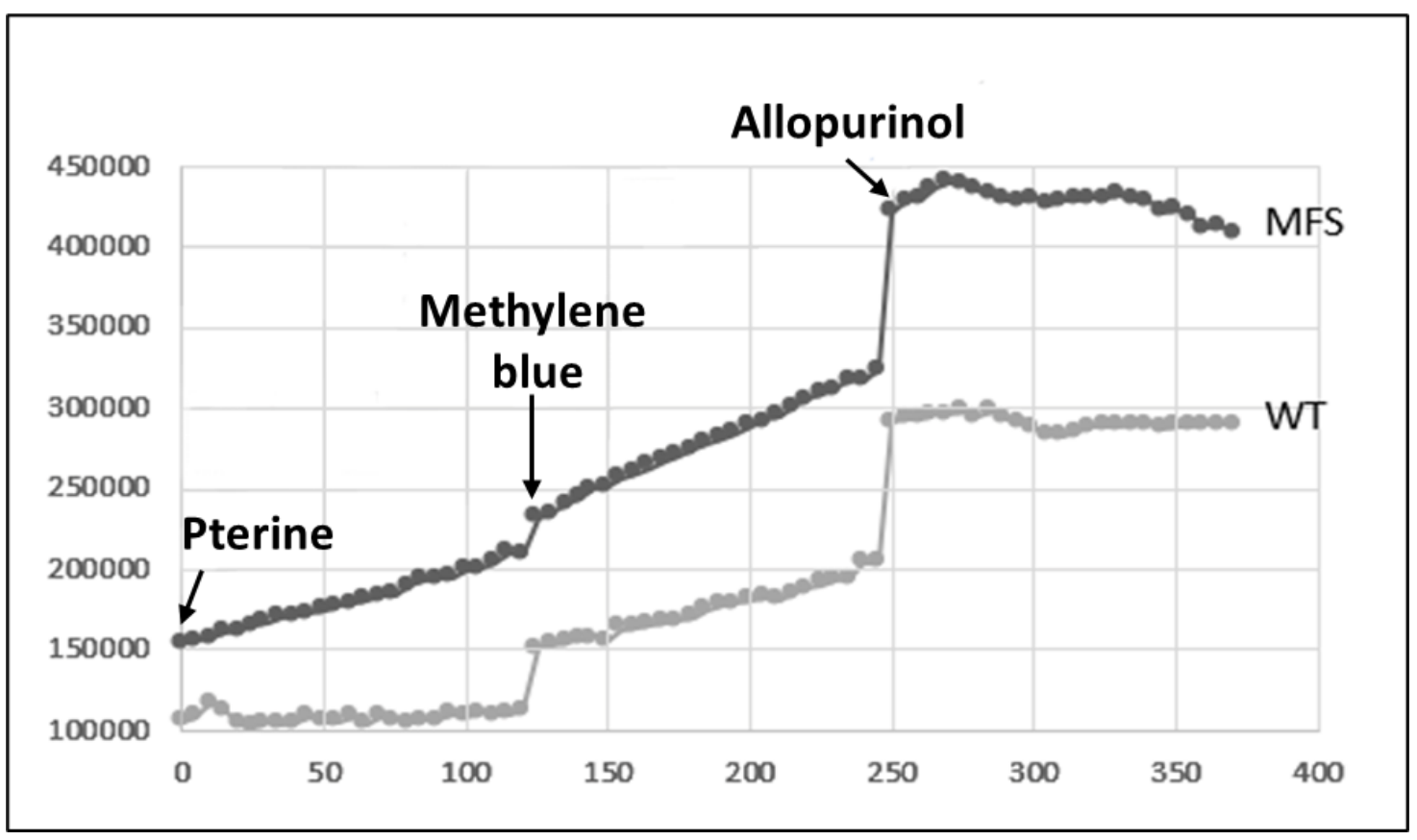

Supplementary Figure 1. Referential positive control assay for XO and XDH enzymatic activities performed in liver lysates. WT and MFS liver lysates had pterine added as specific substrate for XO and methylene blue for total $\mathrm{XOR}(\mathrm{XDH}+\mathrm{XO})$ activity. Allopurinol is added at the end of the assay to check its effectiveness in inhibiting total XDH activity. 
bioRxiv preprint doi: https://doi.org/10.1101/2021.10.13.464182; this version posted October 14, 2021. The copyright holder for this preprint (which was not certified by peer review) is the author/funder. All rights reserved. No reuse allowed without permission.

Preventive treatment/PE (12 weeks)

Palliative treatment/PA1 (16 weeks)

Palliative treatment/PA2 (28 weeks)

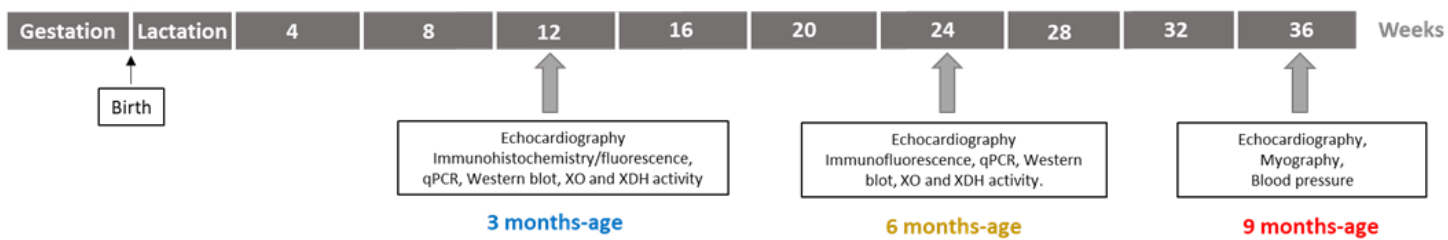

Supplementary Figure 2. Representative scheme of the experimental protocols for allopurinol treatments. PE: preventive allopurinol (ALO) treatment (12 weeks); PA: palliative treatments \#1 (PA1) and \#2 (PA2). The difference between them is the duration of ALO treatments, which for PA1 is 16 weeks (6 month-old mice) and for PA2 is 24 weeks ( 9 month-old mice). Each endpoint duration protocol has a different code color, which is maintained for the figures and supplemental figures shown throughout the manuscript: blue ( 3 months of age), green (6 months of age) and red (9 months of age). 

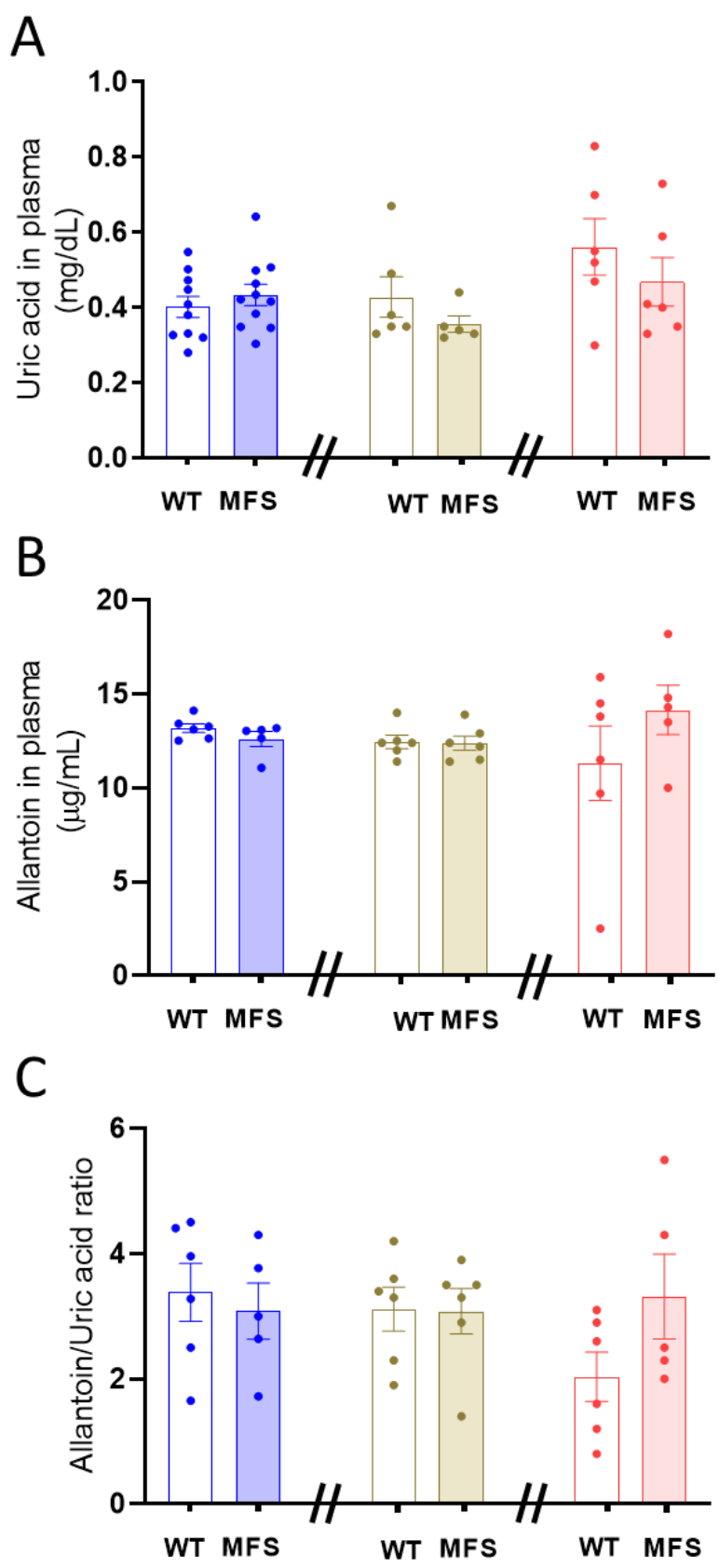

Supplementary Figure 3. Uric acid and allantoin blood plasma levels are not altered in MFS mice. Blood plasma levels of uric acid (A), its catabolite allantoin (B) and their ratio (Allantoin/uric acid) (C) measured in WT and MFS mice of different ages (3-, 6-, and 9-months old). Statistical analysis: Kruskal-Wallis with Dunn's multiple comparison test. Number of samples analyzed: 5-12. 


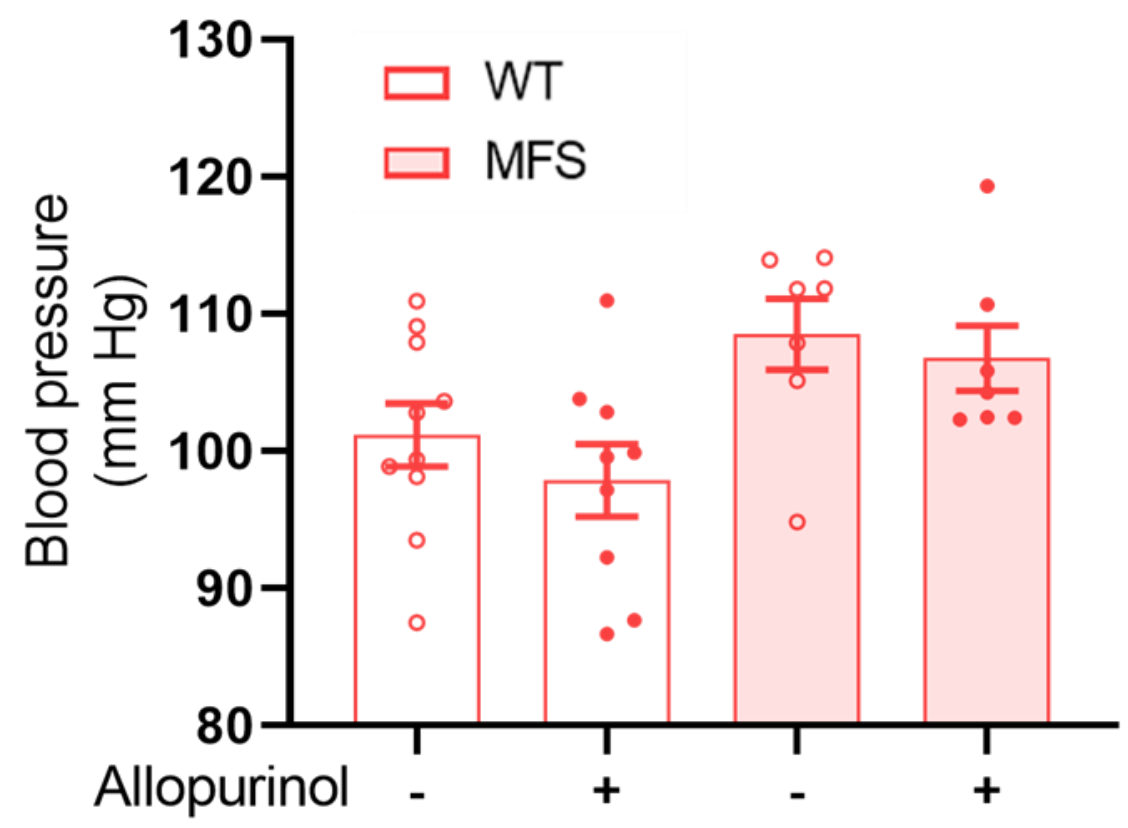

Supplementary Figure 4. Allopurinol does not alter systolic blood pressure. Systolic blood pressure measurements in 9 month-old WT and MFS mice palliatively treated with allopurinol for 28 weeks (PA2). Statistical analysis: Kruskal-Wallis with Dunn's multiple comparison test. Number of animals analyzed: 6-10. 

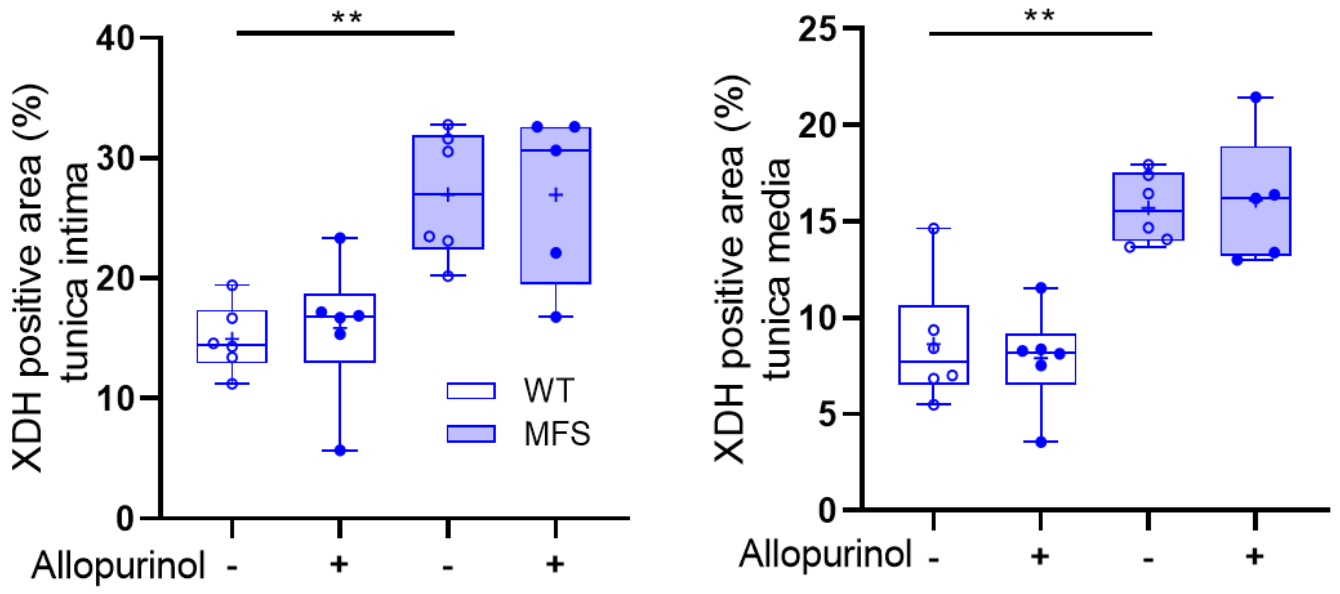

Supplementary Figure 5. XDH protein levels are not affected by allopurinol treatments. Quantitative analysis of the HRP stained aortic tunicae intima and media with anti-XOR antibody of 3-month-old WT and MFS mice after preventive (PE) allopurinol treatment. Statistical test analyses: Two-way ANOVA and Tukey post-test. ${ }^{* *,++} P \leq 0.01$; *Significance between genotype; +significance between treatments. Number of aortae analyzed: 6 . 


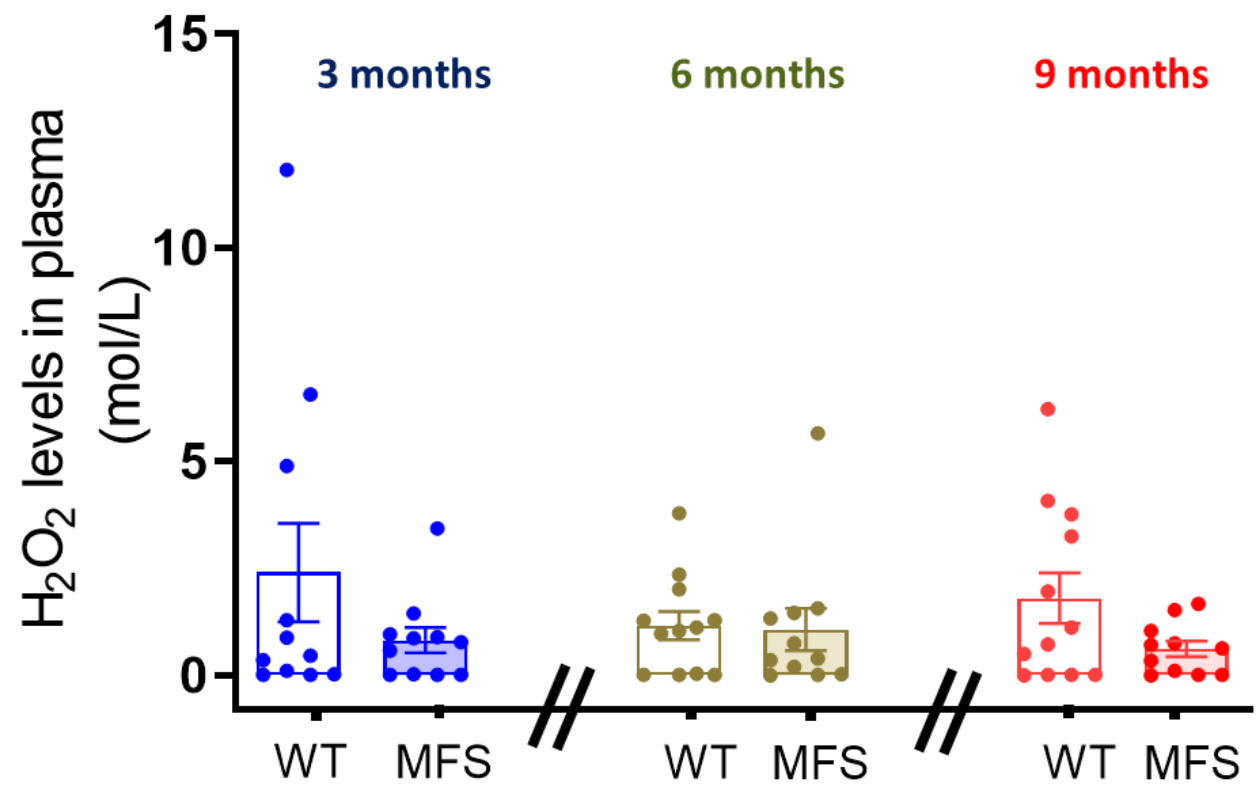

Supplementary Figure 6. $\mathrm{H}_{2} \mathrm{O}_{2}$ plasma levels do not change with age in MFS mice. $\mathrm{H}_{2} \mathrm{O}_{2}$ levels in the blood plasma of WT and MFS of different ages (3-, 6-, and 9-months). Statistical analysis: Kruskal-Wallis with Dunn's multiple comparison test. Number of samples analyzed: 12-14. 

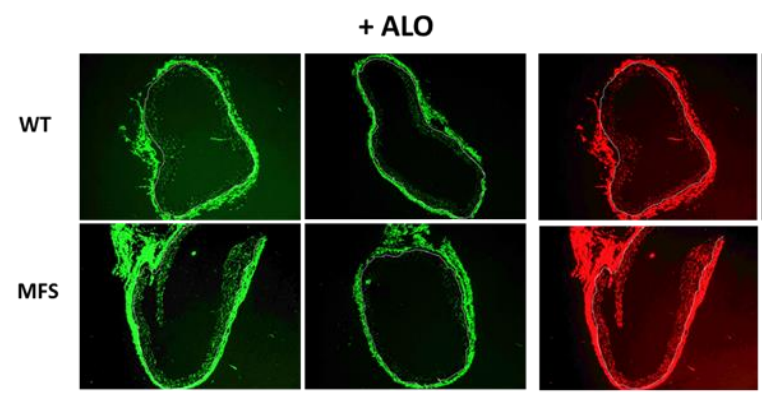

+ ALO
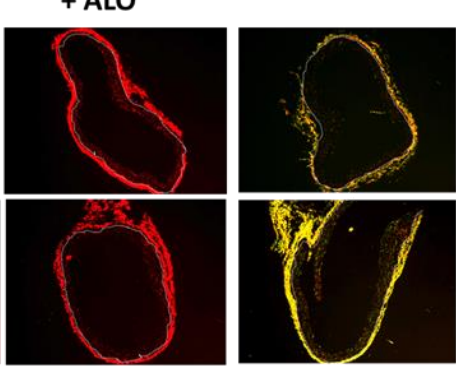

$+\mathrm{ALO}$

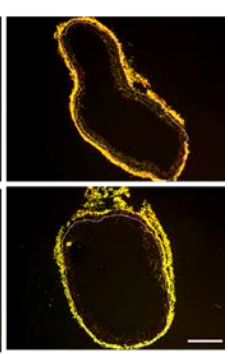

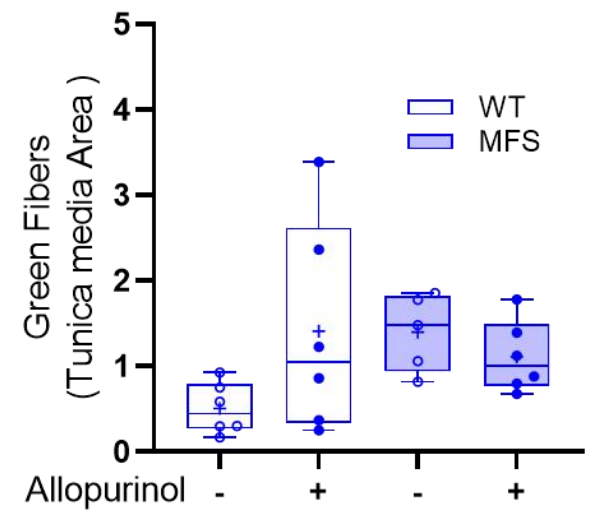

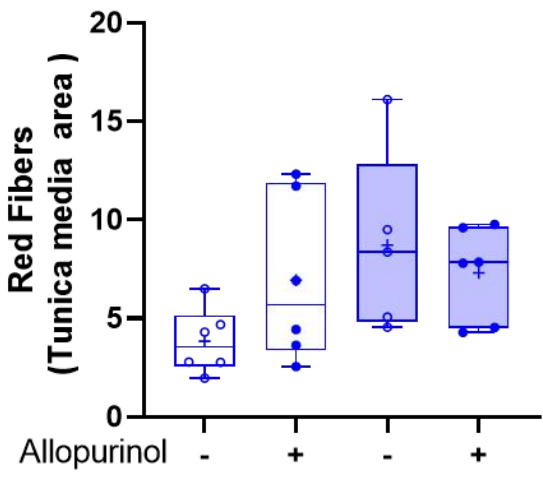

Supplementary Figure 7. Preventive treatment with allopurinol does affect the collagen content and its maturation state in the media of MFS mice. Immature (green) and mature (red) collagen fibers of the tunicae media and adventitia of WT and MFS aortae stained with Picrosirius red visualized under the polarized microscope. WT and MFS mice treated or not with allopurinol in a preventive manner (PE). Representative fluorescent images of the whole aorta where white dashed lines display the limit between tunicae media (inner) and adventitia (outer). The respective quantitative analysis of both types of collagen fibers is also shown. Bar, $100 \mu \mathrm{m}$. Statistical test Kruskal-Wallis and Dunn's multiple comparison tests. ${ }^{* * *} \mathrm{P} \leq 0.001$ and ${ }^{+} \mathrm{P} \leq 0.05$; *significance between genotype; ${ }^{+}$significance between treatments. Number of aortae analyzed: 5-6. 


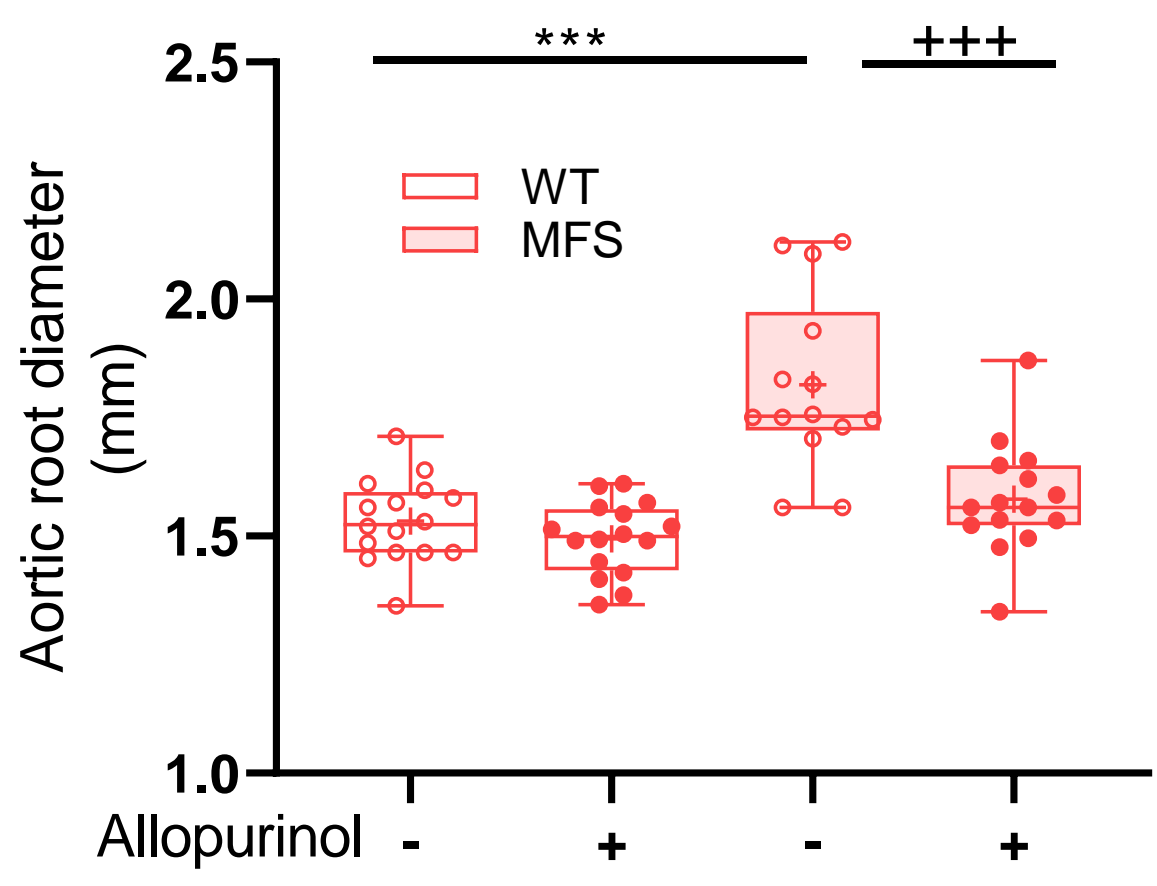

Supplemental Figure 8. Aortic root diameter measured by ultrasonography of 9-month-old WT and MFS mice palliatively treated or not with allopurinol for 28 weeks (PA2). Statistical analyses: Two-way ANOVA and Tukey post-test (A and B). ${ }^{* * *},{ }^{+++} P \leq 0.001$; *significance between genotype; +significance between treatments. Number of animals analyzed: $14-16$. 
bioRxiv preprint doi: https://doi.org/10.1101/2021.10.13.464182; this version posted October 14, 2021. The copyright holder for this preprint (which was not certified by peer review) is the author/funder. All rights reserved. No reuse allowed without permission.

SUPPLEMENTARY TABLES (S1-S6)

Supplementary Table 1. Primers used in RT-PCR analysis in MFS mice

\begin{tabular}{|l|l|}
\hline Gene & Primer sequences \\
\hline $\boldsymbol{X d h}$ & Fw: 5' - GGAGATATTGGTGTCCATTGTG -3' \\
& Rv: 5' - CCTGCTTGAAGGCTGAGAAA -3' \\
\hline Gapdh & Fw: 5' - TTGATGGCAACAATCTCCAC -3' \\
& Rv: 5' - CGTCCCGTAGACAAAATGGT-3' \\
\hline
\end{tabular}

Supplementary Table 2. Echocardiographic values of the aortic root diameter (in $\mathrm{mm}$ ) of WT and MFS mice subjected to palliative treatment (PA1) in the presence (+) or absence (-) of allopurinol after treatment for 16 weeks (from 8-to 24-week-old mice). Graphic shown in Figure 3A1. Data pooled by sex is included.

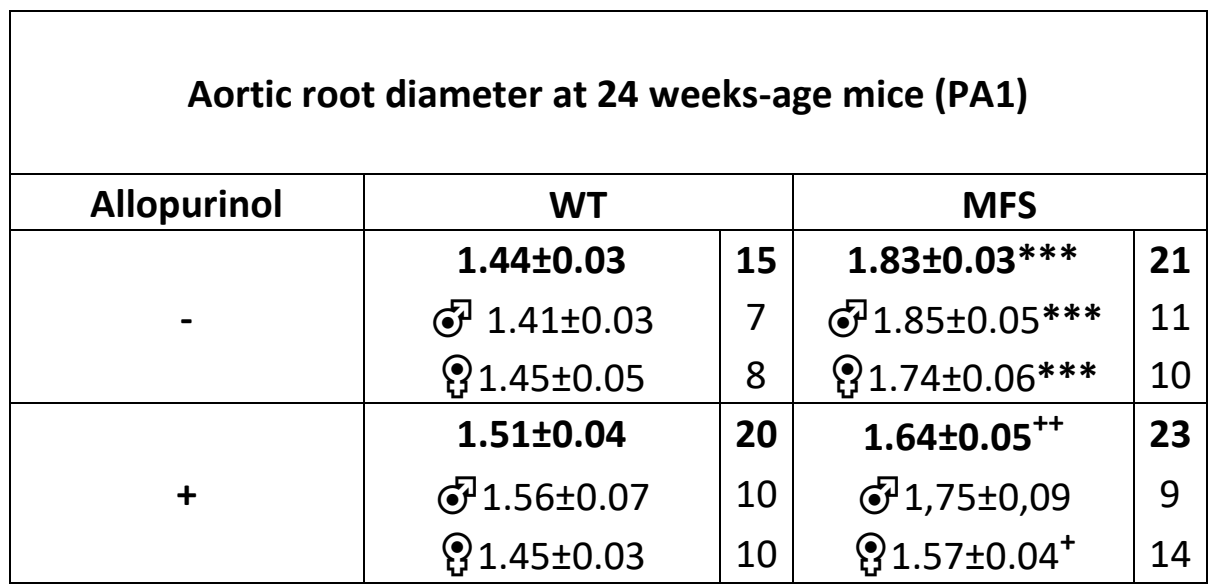

Statistical analysis: Three-Way ANOVA. *Indicates the statistical significance of WT vs. MFS mice of the same age; ${ }^{+}$ndicates the statistical significance between WT or MFS mice of different ages. ${ }^{* * *} p \leq 0.001 ;{ }^{++} p \leq 0.01 ;{ }^{+} p \leq 0.05$. No statistical differences were obtained when comparing the sex of mice. The number of animals is indicated on the right of each column. Sex: $f$ males, \& females. 
bioRxiv preprint doi: https://doi.org/10.1101/2021.10.13.464182; this version posted October 14, 2021. The copyright holder for this preprint (which was not certified by peer review) is the author/funder. All rights reserved. No reuse allowed without permission.

Supplementary Table 3. Echocardiographic values of the aortic root diameter (in $\mathrm{mm}$ ) of WT and MFS mice subjected to preventive treatment (PE) in the presence (+) and absence (-) of allopurinol. Graphics shown in Figure 3B1.

\begin{tabular}{|c|c|c|c|c|}
\hline \multicolumn{5}{|c|}{ Aortic root diameter at 12 weeks-age mice (PE) } \\
\hline Allopurinol & WT & MFS \\
\hline- & $1.45 \pm 0.04$ & 11 & $1.71 \pm 0.04^{* * *}$ & 9 \\
\hline+ & $1.27 \pm 0.04$ & 11 & $1.35 \pm 0.04^{+++}$ & 10 \\
\hline
\end{tabular}

Statistical analyses: Two-way Anova followed by Tukey post-test. *Indicates the statistical significance of WT vs. MFS mice of the same age; +Indicates the statistical significance between WT or MFS mice of different ages. ${ }^{* * *},{ }^{+++} p \leq 0.001$; ${ }^{++} p \leq 0.01 ;{ }^{*} p \leq 0.05$. The number of animals is indicated on the right of each column.

Supplementary Table 4. Echocardiographic values of the aortic root diameter (in $\mathrm{mm}$ ) of WT and MFS mice subjected to palliative treatment (PA2) with allopurinol for 28 weeks (from 8 to 36 weeks-old mice). Data pooled for sex is also shown. Graphics shown in Supplementary Figure 10.

\begin{tabular}{|c|c|c|c|c|}
\hline \multicolumn{5}{|c|}{ Aortic root diameter at 36 weeks-age mice (PA2) } \\
\hline Allopurinol & WT & & MFS & \\
\hline \multirow{3}{*}{ - } & $1.53 \pm 0.02$ & 16 & $1.82 \pm 0.05 * * *$ & 14 \\
\hline & fo $1.54 \pm 0.04$ & 7 & 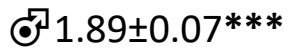 & 8 \\
\hline & 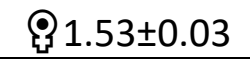 & 9 & 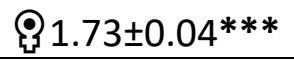 & 6 \\
\hline \multirow{3}{*}{+} & $1.49 \pm 0.02$ & 16 & $1,58 \pm 0,03^{+++}$ & 15 \\
\hline & क $1.52 \pm 0.03$ & 7 & fP $1.58 \pm 0.05^{++}$ & 8 \\
\hline & \$ $1.48 \pm 0.04$ & 9 & \$ $1.58 \pm 0.03^{+}$ & 7 \\
\hline
\end{tabular}

Statistical analysis: Three-Way ANOVA. *Indicates the statistical significance of WT vs. MFS mice of the same age; ${ }^{+}$ndicates the statistical significance between WT or MFS mice of different ages. ${ }^{* \star *},{ }^{++} p \leq 0.001 ;{ }^{++} p \leq 0.01 ;{ }^{+} p \leq 0.05$. No statistical differences were obtained when comparing the sex of mice. The number of animals is indicated on the right of each column. Sex: $f$ males, \& females. 
bioRxiv preprint doi: https://doi.org/10.1101/2021.10.13.464182; this version posted October 14, 2021. The copyright holder for this preprint (which was not certified by peer review) is the author/funder. All rights reserved. No reuse allowed without permission.

Supplementary Table 5. Potency $\left(\mathrm{pEC}_{50}\right)$ and maximum response $\left(\mathrm{E}_{\max }\right)$ of the concentration-response curve (CRC) values for ACh- and NTP-induced relaxation response (\%) in the ascending aorta from WT and MFS mice (9 months-old) in the presence $(+)$ or absence $(-)$ of allopurinol.

\begin{tabular}{|c|c|c|c|c|c|c|c|c|c|}
\hline \multirow{2}{*}{\multicolumn{2}{|c|}{$\frac{\text { Ascending aorta }}{\text { Allopurinol }}$}} & \multicolumn{4}{|c|}{ WT } & \multicolumn{4}{|c|}{ MFS } \\
\hline & & - & & + & & - & & + & \\
\hline$C R C$ & $E_{\max }(\% F E)$ & $88.25 \pm 2.99$ & 6 & $89.70 \pm 2.52$ & & $82.09 \pm 4.65$ & & $80.06 \pm 5.45$ & \\
\hline$A C h$ & $p E C_{50}$ & $7.52 \pm 0.10$ & 0 & $7.69 \pm 0.08$ & 4 & $6.85 \pm 0.13 * * *$ & 0 & $7.49 \pm 0.19$ & \\
\hline$C R C$ & $E_{\max }(\% F E)$ & $90.21 \pm 4.75$ & 5 & $102.8 \pm 2.94$ & 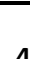 & $102.1 \pm 3.45$ & & $106.7 \pm 7.27$ & \\
\hline NTP & $p E C_{50}$ & $7.69 \pm 0.11$ & J & $7.96 \pm 0.07$ & 4 & $7.96 \pm 0.08$ & 4 & $7.66 \pm 0.18$ & 5 \\
\hline
\end{tabular}

*Indicates the statistical significance of WT vs. MFS mice of the same age; ${ }^{* * *} p \leq 0.001$. Two-way ANOVA followed by Tukey post-test. The number of animals is indicated on the right of each column.

Supplementary Table 6. $\mathrm{KCl}$ vascular tone was expressed as force units $(\mathrm{mN})$. Potency $\left(p E_{50}\right)$ and maximum response $\left(E_{\max }\right)$ of the concentration-response curve $(\mathrm{CRC})$ values for Phe-induced contraction response $(\%)$ in the ascending aorta of 9-month-old WT and MFS mice in the presence $(+)$ or absence $(-)$ of allopurinol.

\begin{tabular}{|c|c|c|c|c|c|c|c|c|c|}
\hline Asce & ling aorta & \multicolumn{4}{|c|}{ WT } & \multicolumn{4}{|c|}{ MFS } \\
\hline \multicolumn{2}{|c|}{ Allopurinol } & \multicolumn{2}{|l|}{-} & \multicolumn{2}{|l|}{+} & \multicolumn{2}{|l|}{-} & \multicolumn{2}{|l|}{+} \\
\hline$K C l$ & $E_{\max }(m N)$ & $4.70 \pm 0.52$ & 6 & $4.56 \pm 0.80$ & 5 & $4.43 \pm 0.60$ & 6 & $4.32 \pm 0.49$ & 6 \\
\hline \multirow{3}{*}{$\begin{array}{l}\text { CCR } \\
\text { Phe }\end{array}$} & F $\quad(0 / K C I)$ & $52.67 \pm 6.6$ & \multirow{3}{*}{6} & $31.18 \pm 9.4$ & \multirow{3}{*}{5} & $75.32 \pm 19.0$ & \multirow{3}{*}{6} & $64.70 \pm 20.2$ & \multirow{3}{*}{5} \\
\hline & $\Sigma_{\max }\left(\% \mathrm{~K}^{\prime}(1)\right.$ & 0 & & 4 & & 6 & & 1 & \\
\hline & $p E C_{50}$ & $6.46 \pm 0.28$ & & $7.28 \pm 0.80$ & & $6.25 \pm 0.61$ & & $6.35 \pm 0.72$ & \\
\hline
\end{tabular}

